Article

\title{
Understanding the Perceptual Spectrum of Commercial Perfumes as a Basis for a Standard Sensory Wheel of Fragrances
}

\author{
Manuel Zarzo \\ Department of Applied Statistics, Operations Research and Quality, Universitat Politècnica de València, \\ Camino de Vera s/n, 46022 Valencia, Spain; mazarcas@eio.upv.es; Tel.: +34-963877490
}

Received: 19 October 2019; Accepted: 23 December 2019; Published: 25 December 2019

\begin{abstract}
Given the enormous number of perfumes available on the market, it is of interest to guide consumers in their purchase of a new fragrance. One approach is to project the multidimensional perceptual space of scents on a two-dimensional sensory map based on meaningful dimensions. One of the pioneering studies on this issue mapped 94 commercial perfumes according to two axes. Such an odor map is discussed here in detail by applying Principal Component Analysis to the numeric odor description of 176 fragrances. Quantitative odor profiles were obtained from Fragrantica's website and three fragrances guides published by Haarmann \& Reimer, Michael Edwards, and the French Society of Perfumers. A sensory map was obtained that reflected the similarities and dissimilarities between those odor descriptors most commonly used in perfumery. This representation was consistent with other related plots that have been previously reported. One dimension discriminated between fragrances targeted at men versus women. An orthogonal factor distinguished perfumes for daytime versus nighttime wear. These ratings, as well as seasonal preferences, could be estimated based on the main odor character attributes applied to describe the scent. The results provide a scientific basis for the comprehensive classification of commercial perfumes compiled by Edwards according to his famous "Fragrance Wheel".
\end{abstract}

Keywords: odor analysis; fragrance; olfactory psychophysics; perceptual freshness; odor descriptor

\section{Introduction}

Up until the late 1960s, women usually remained faithful to one perfume over years [1]; however, since the 1970s, people have started to use several brands and to switch frequently between them. Large fragrance companies became aware of the need for a classification of perfumes based on their smell, not on brands. The German company Haarmann \& Reimer (H\&R) published a "Genealogy of Perfumes" [2], which was updated over the following years. The "H\&R Fragrance Guide" [3] lists a set of 820 perfumes under seven families and different subfamilies. A chart based on this classification has been re-edited several times [4], and the current online version [5] classifies 777 items. Other similar charts are also currently available [6].

In 1984, the French Society of Perfumers (FSP) published a catalog based on seven olfactory families, which were nearly the same as the H\&R guide. The third edition comprised 807 fragrances [7]. An updated online version of the FSP guide [8] contains 1208 men's, 2522 women's, and 388 unisex fragrances. A handbook published by Groom [9] classifies about 1800 perfumes sold in the UK market based on odor categories, which are almost coincident with the H\&R guide.

Firmenich SA (Geneva, Switzerland) edited ca. 1975 a guide called the "Bouquet de la Parfumerie", which grouped feminine fragrances by families and then by groups. On the basis of this catalog, Michael Edwards published a directory with about 300 perfumes [10] that has been re-edited annually 
and that contained 2700 items in 2001 and 5730 in 2008. Olfactory groups are organized in a sensory representation known as the "Fragrance Wheel" [11], which has become very popular. The online version (www.fragrancesoftheworld.info) comprises over 19,500 perfumes and is available by paid subscription. Firmenich created, in 2001, the Osmoz website, which currently classifies over 8000 perfumes and describes their dominating olfactory notes [12]. Fragrantica's website (www.fragrantica.com) arranges more than 30,000 perfumes according to the same seven olfactory groups as the FSP guide, though the subgroups are different. Another directory describing the two most prominent notes of 1800 perfumes is also available [13].

These classification systems are valuable tools for guiding consumers in their purchase of a new fragrance. Another approach is to project the multidimensional perceptual space of scents on a two-dimensional (2D) sensory map. This is the case with the "Field of Odors" developed by Jaubert et al. [14]. Other sensory maps of perfumery descriptors have been reported based on a multivariate analysis of large compilations of olfactory descriptions [15].

One of the first 2D charts of commercial fragrances was developed around 1985 by the Swiss company Givaudan [16] (pp. 276-277): it shows analogies of feminine and masculine fragrances based on the main olfactory groups. Since the 2010 edition, Edwards's Wheel has displayed 14 categories around a central hub, and it can also be regarded as a 2D perfume chart. Dragoco (Holzminden, Germany) mapped 91 women's perfumes inside a polygon called the "Hexagon of Fragrance Families", so that each side corresponds to a different odor category [17]. On the basis of sensory studies carried out at Dragoco by Jellinek, 94 commercial fragrances were plotted in the so-called "Map of the World of Fragrances", which was based on two meaningful axes: "floral" versus "not floral" and "cool" versus "warm" [1].

Despite the great effort conducted in the decades of the 1980s and 1990s to shed some light on how to classify and map commercial perfumes, this topic received little attention in subsequent years. Actually, a review on this subject did not mention other relevant perfume maps [18]. Some studies have derived 2D charts of fragrances based on sorting tasks of consumers [19] or semantic methods of odor description [20,21], but the number of samples assessed was very small. Other authors have developed a methodology to obtain numeric olfactory profiles of fragrances based on eight descriptors [22,23], which is a promising method for deriving sensory charts in further studies.

Jellinek's fragrance map [1] was based on two dimensions generated spontaneously by a group of consumers through free associations with a set of contemporary perfumes. One target of the present work was to study whether a multivariate analysis of numeric odor descriptions of perfumes obtained from expert sources such as Fragrantica's website and the H\&R guide would lead to the same underlying factors. The resulting multivariate projection of odor descriptors on two principal components was compared to related plots reported by other studies as well as to the well-known Fragrance Wheel [11]. The purpose was to provide a scientific foundation for this fragrance classification system, which has become probably the most trusted reference in the industry. Nonetheless, other sensory wheels have been proposed for perfume descriptions, such as the Discodor [24], the Hexagon of Fragrance Families [17], and the Drom Fragrance Circle (reproduced by Reference [25]).

Another objective was to provide a meaningful interpretation for the two principal dimensions governing the perceptual space of scents. For this purpose, regression models were developed to estimate if a given perfume is more suitable for daytime or nighttime wear. Seasonal preferences were also studied in order to understand which olfactory notes make a fragrance more suitable for summer, spring, or fall. The supporting hypothesis was that preference for daytime and summertime are tightly correlated [26]. This issue is well-known in perfumery, but this correlation was quantified here statistically. In perfumery, "cool" refers to the specific trigeminal effect associated with camphoraceous smells. Olfactory qualities that increase or decrease this particular odor character were also studied. Another regression equation was fitted to better understand which qualities are able to discriminate between men's and women's fragrances. An appropriate understanding of such underlying dimensions is important from a scientific standpoint and may be useful for brands in their bids to launch successful new items in this competitive market. 


\section{Materials and Methods}

\subsection{Comparison of Two Fragrance Maps and Discussion of the Sample}

The Map of the World of Fragrances [1] displays 94 perfumes. The horizontal axis basically discriminates between "floral" and "nonfloral" scents, while the vertical dimension is interpreted as "warm" versus "cool". The coordinate position of each fragrance along the $x$ axis was obtained from this map by using an ordinary ruler graduated in centimeters. These measurements were multiplied by a factor in order to express them on a scale from -5 (the most dissimilar to floral) up to +5 (floral). These values will be called hereafter "floral scores" $\left(S_{\text {floral }}\right)$. Similarly, the $y$ coordinates were expressed from -5 (warm) up to +5 (cool), and they were named "cool scores" $\left(S_{\text {cool }}\right)$.

Another sensory map of 140 commercial perfumes based on equivalent dimensions was obtained by Jellinek in a previous research [27]. The coordinate positions were also measured on a scale from -5 to +5 , and the same names were assigned (horizontal axis: $S_{\text {floral }}$; vertical axis: $S_{\text {cool }}$ ). A set of 58 fragrances appear in both maps, and it was checked that their $S_{\text {floral }}$ scores were correlated $\left(r_{58}=0.85\right.$, $p<0.0001)$. The value indicated as a subscript of Pearson's correlation coefficient $(r)$ corresponds with the number of observations included in the analysis. Analogously, their $S_{\text {cool }}$ scores were also correlated $\left(r_{58}=0.88, p<0.0001\right)$. Hence, the average value was computed for these 58 items in order to obtain a more accurate estimation. In the end, coordinate positions were available for a set of 176 fragrances, which will be referred to hereafter as Jellinek's perfumes.

It is of interest to discuss whether they can be considered to be a representative sample of the European market in the 1990s. Given that all of them are included in the H\&R guide, I checked how these 176 fragrances were classified in this catalog by computing the percentage of items contained in each category (e.g., 11.9\% of Jellinek's perfumes targeted at women are regarded as "floral-ambery"). Such frequencies were compared to the percentage of fragrances listed under each category of the H\&R guide (e.g., 9.8\% of women's perfumes in this directory are classified as "floral ambery").

\subsection{Daytime versus Nighttime Preference and Seasonal Preference}

The database compiled from Fragrantica's website (FrD) contains 16,275 women's, 6115 men's, and 7262 unisex fragrances (accessed July 2015). Unfortunately, 5 out of the 176 perfumes are not included. This website allows people to vote on whether a given fragrance is regarded as more suitable for daytime or nighttime wear. It is also possible to choose the season considered as most appropriate. People can also vote "love", "like", or "dislike". This information is displayed graphically with bar charts that do not indicate the relative frequencies. However, these percentages were obtained by measuring the length of each bar using a metric scale and by considering bars for day and night as corresponding to $100 \%$, which also applies to the four seasons (Figure 1a).

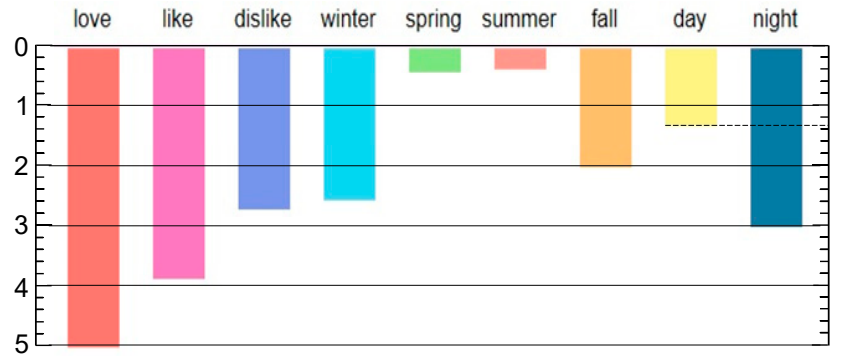

(a)

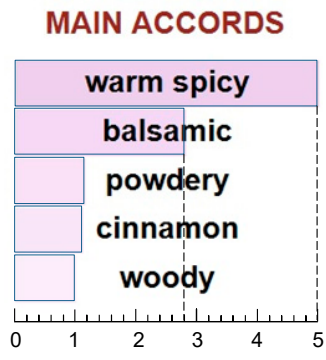

(b)

Figure 1. Olfactory profiles of the fragrance Cinnabar according to Fragrantica's website. (a) Preference profile obtained from consumers. On the vertical scale (established from 0 to 5 ), day $=1.35$ and night $=3$, which leads to the percentages: day $=1.35 / 4.35=31 \%$, night $=100 \%-31 \%=69 \%$. Seasonal percentages were obtained analogously. (b) Description of main accords on a $0-5$ scale (the maximum value corresponds to the most noticeable note). 
The percentage of people who voted "day" or "night" was called $P_{\text {day }}$ or $P_{\text {night }}$, respectively. The percentage of users who chose a particular season was denoted as $P_{\text {winter }}, P_{\text {spring }}, P_{\text {summer }}$, and $P_{\text {fall }}$. The parameters $P_{\text {love }}, P_{\text {like }}$, and $P_{\text {dislike }}$ were computed as well. It turns out that $P_{\text {night }}$ was tightly correlated with $P_{\text {winter, }}$, and the same was found by comparing $P_{\text {day }}$ to $P_{\text {summer }}$. These relationships were studied by means of linear regression.

\subsection{Quantitative Odor Profiles from Fragrantica's Website}

Fragrantica also indicates the set of five or six odor descriptors that are most noticeable. This information is displayed as a bar chart called "main accords". The length of each bar was measured using an ordinary ruler, and the values were expressed on a continuous scale from 0 to 5 (Figure 1b). The maximum value was assigned to the largest bar, whose length was the same for all fragrances. The ratings for "woody" are denoted as $X_{w o o d y}$, and so on for the rest of the attributes.

The total number of descriptors was 32, but only 18 of them were considered because the rest had a low frequency of occurrence $(n<9)$. The following procedure was applied with the minority attributes. "Rose", "yellow floral", "white floral", and "floral" refer to very similar scents; thus, their ratings were merged together in a single variable by computing for each fragrance the maximum (i.e., $\left.X_{\text {floral }}=\max \left\{X_{\text {rose }}, X_{\text {yellow_floral }}, X_{\text {whiteffloral }}, X_{\text {floral }}\right\}\right)$. The occurrence was very low for $X_{\text {soft-spicy }}(n=2)$, but $X_{\text {warm-spicy }}$ was a related variable with a high occurrence $(n=58)$. In this case, we could discard $X_{\text {soft-spicy }}$ or transfer the two nonzero values of this variable to $X_{\text {warm-spicy. }}$. Although they refer to a distinct smell, the second option was chosen as an effort to retain as much information as possible.

There are three perfumes described as "cinnamon" in the FrD, which were additionally regarded as "warm spicy", and one of them was also rated as "sweet". Given the apparent sweet odor of cinnamon, this variable was disregarded, but their values were transferred to "sweet". Analogously, very few fragrances were rated as "vanilla" $(n=8)$ or "honey" $(n=6)$. Such frequencies were too low for the multivariate analysis, but these materials smell distinctly sweet; hence, such ratings were assigned to "sweet", taking into account the higher occurrence of this descriptor $(n=32)$. Thus, $X_{\text {sweet }}$ $=\max \left\{X_{\text {vanilla }}, X_{\text {honey }}, X_{\text {cinnamon }}, X_{\text {sweet }}\right\}$. The five fragrances rated as $X_{\text {patchouli }}>0$ were also described as "woody" but not as "earthy". Considering that patchouli smells woody-earthy [28], it was decided to discard $X_{\text {patchouli }}$ and transfer the nonzero values to $X_{\text {earthy }}$.

Taking into account that leathery fragrances are characterized by dry notes of tobacco and burnt-smoky wood [11], "tobacco" $(n=2)$ and "smoky" $(n=6)$ were merged with "leather" $(n=18)$. Half of fragrances rated as "tobacco" or "smoky" were also described as "leather", which supports the criterion of transferring their values to $X_{\text {leather }}$. This approach might be arguable because the smells of tobacco, smoke, and leather are actually distinct. This might appear to be a simplistic shortcut to simplify the work; however, the purpose was to preserve the maximum amount of information for those variables that needed to be discarded given their low occurrence. Finally, "marine", "fresh", and "ozonic" were disregarded given their low occurrence $(n<4)$.

Fragrantica's profile of Cinnabar by Estée Lauder (1978) is illustrated in Figure 1b: $X_{\text {warm-spicy }}=5$, $X_{\text {balsamic }}=2.8, X_{\text {powdery }}=1.1, X_{\text {cinnamon }}=1.1$, and $X_{\text {woody }}=1$. This information could be interpreted as follows: the warm-spicy character was the most noticeable; "balsamic" was also a characteristic quality of the smell; and finally, "powdery", "cinnamon", and "woody" notes were also perceptible to some degree. For the remaining descriptors not contained in Fragrantica's main accords, the scores were smaller than one, and they were regarded as zero since the exact values were unknown.

\subsection{Dichotomic Matrix of Odor Profiles}

Additional olfactory information was incorporated based on the semantic description provided by H\&R [3]. For each descriptor in this guide, an indicator variable was created that took the value of 1 for perfumes labeled with that attribute either in the top, middle, or base note or zero otherwise, resulting in a set of 28 variables. The top note corresponds with the first impression perceived when 
sniffing a fragrance, which is due to the most volatile materials; the middle note represents the main body or heart of the blend, and the base note yields the characteristic lasting scent of any fragrance [29]. These dichotomic variables were called $I_{H R g r e e n}, I_{H R f l o r a l}$, etc. (Table 1). Thus, $I_{H R}$ means an "indicator variable extracted from the H\&R guide". Unfortunately, the true olfactory strength of ingredients based on their detection threshold was not available, although this is critical to perception much more than to the marketing presentation of perfumes featuring trendy notes.

By checking the olfactory variables with the highest positive correlation with each descriptor, it was found that those with fewer than 11 occurrences did not provide useful information because the similarities obtained were not consistent with odor relationships well known in perfumery. Hence, such indicator variables were discarded. "Exotic" $(n=17)$ and "elegant" $(n=14)$ were also disregarded given their subjectivity. The final list comprised 16 attributes (Table 1).

A set of eight additional indicator variables was generated as follows. $I_{\text {aldehyde }}$ was coded as 1 for perfumes described as "soft floral" in Edwards's guide (EdG) or as "aldehydic" according to the classifications of H\&R, FSP, or the FrD. Similarly, $I_{\text {chypre }}$ was coded as 1 for perfumes classified as chypre (mossy woods) in at least one of these guides. I $I_{\text {fruity }}$ was created analogously. $I_{\text {aromatic }}$ accounts for fragrances labeled as "aromatic" or "fougère" in any classification. Although "aromatic" is somewhat subjective because the term was applied in former times to describe the fragrance impression of sweet balsams, in modern perfumery it usually refers to the fragrance family born after the famous perfume Fougère Royale that was created in 1882 [30]. Hence, "aromatic" and "fougère" were considered to be equivalent categories following the criterion of Edwards [11], Groom [9], and Fragrantica.

Another variable, $I_{E D f l o r a l}$, took the value of 1 for perfumes in EdG classified as floral, soft-floral, or floral-oriental. Similarly, $I_{E D o r i e n t a l}=1$ for those regarded as oriental, floral-oriental, soft-oriental, or woody-oriental. Apart from the classification according to the Fragrance Wheel, EdG also indicates if a given perfume is perceived as fresh, crisp, classical, or rich. On the basis of this information, an indicator variable called $I_{E D f r e s h}$ was coded as 1 for all fragrances regarded as "fresh" and was coded as 0 otherwise. Finally, another descriptor named $I_{F E M}$ was created, which took the value of 1 for feminine fragrances and 0 for those targeted at men. The two unisex ones were coded as $I_{F E M}=0.5$.

Table 1. List of variables compiled from Fragrantica's website $(\mathrm{FrD})$ and different catalogs for the set of 176 fragrances used by Jellinek [1,27]: number of observations $\left(N_{o b s}\right)$, number of variables excluded $\left(N_{\text {excl }}\right)$, and variables included in the multivariate analysis (48 in total).

\begin{tabular}{|c|c|c|c|c|c|c|}
\hline Source & $N_{o b s}$ & \multicolumn{4}{|r|}{ Variables } & Code $^{1}$ \\
\hline Jellinek $[1,27]$ & 176 & -5 to 5 & $2^{2}$ & 0 & & \\
\hline FrD: from consumer preferences & 171 & in $\%$ & 3 & 6 & $P_{\text {day }}, P_{\text {night }}, P_{\text {spring }}, P_{\text {summer }}, P_{\text {fall }}, P_{\text {winter }}$ & $\bullet$ \\
\hline FrD: from main accords & 171 & 0 to 5 & 14 & 18 & $\begin{array}{l}X_{\text {aldehydic }}, X_{\text {amber }}, X_{\text {animalic }}, X_{\text {aromatic }}, X_{\text {balsamic }}, X_{\text {citrus }}, \\
X_{\text {earthy }}, X_{\text {floral }}, X_{\text {fresh-spicy }}, X_{\text {fruity }}, X_{\text {green }}, X_{\text {herbal }}, \\
X_{\text {leather }}, X_{\text {musky }}, X_{\text {powdery }}, X_{\text {sweet }}, X_{\text {warm-spicy }}, X_{\text {woody }}\end{array}$ & $\bullet$ \\
\hline $\begin{array}{l}\text { Haarmann \& Reimer (H\&R) } \\
\text { guide [3] }\end{array}$ & 176 & 0 or 1 & 12 & 16 & $\begin{array}{l}I_{\text {HRaldehydic }}, I_{\text {HRambery }}, I_{\text {HRbalsamic }}, I_{\text {HRcitrusy }}, I_{\text {HRfloral }}, \\
I_{\text {HRfresh }}, I_{\text {HRfruity }}, I_{\text {HRgreen }}, I_{\text {HRherbaceous }}, I_{\text {HRleathery }}, \\
I_{\text {HRmossy }}, I_{\text {HRpowdery }}, I_{\text {HRspicy }}, I_{\text {HRsweet }}, I_{\text {HRwarm }}, I_{\text {HRwoody }}\end{array}$ & $\bullet$ \\
\hline Edwards's guide (EdG) [11] & 163 & 0 or 1 & - & 3 & $I_{E D \text { floral }}, I_{E \text { Doriental }}, I_{E D \text { fresh }}$ & - \\
\hline FrD, H\&R [3], FSP [7], EdG [11] & 176 & 0 or 1 & - & 5 & $I_{\text {aldehyde }}, I_{\text {chypre }}, I_{\text {fruity }}, I_{\text {aromatic }}, I_{F E M}$ & घ \\
\hline
\end{tabular}

\subsection{Statistical Analysis}

In the end, 24 dichotomic descriptors were considered (i.e., $16+3+5$ in Table 1): this set will be referred to as "dichotomic matrix of descriptors". This matrix was merged with the one containing Fragrantica's numeric profiles. $P_{\text {day }}, P_{\text {night }}$ and seasonal percentages (i.e., $P_{\text {spring }}, P_{\text {summer }}$, $P_{\text {fall }}, P_{\text {winter }}$ ) were also incorporated, resulting in a final matrix containing 176 observations (perfumes) by 48 variables (Table 1). As one target of this research was to reproduce Jellinek's perfume maps, 
$S_{\text {cool }}$ and $S_{\text {floral }}$ were not included. The preferences $P_{\text {like, }}, P_{\text {dislike }}$, and $P_{\text {love }}$ were also disregarded. Principal component analysis (PCA) was applied to the final matrix using the software SIMCA-P 10.0 (www.umetrics.com). Data columns (variables) were mean-centered and scaled to unit variance prior to the analysis, which is the most common pretreatment.

Principal components (PCs) are linear combinations of the original variables. The projection of observations (perfumes) over the directions in the multivariate space determined by PC1 and PC2 are called $t(1)$ and $t(2)$ scores, respectively. The scatterplot of $t(2)$ versus $t(1)$ can be regarded as a $2 \mathrm{D}$ sensory map of commercial perfumes. It was compared to the consensus mapping of Jellinek by studying the correlation of these scores with $S_{\text {cool }}$ and $S_{\text {floral }}$. The contributions of variables (i.e., odor descriptors in this case) in the formation of a given component are called loadings, with $p(1)$ and $p(2)$ being the loadings corresponding to $\mathrm{PC} 1$ and $\mathrm{PC} 2$, respectively.

The scatterplot of $p(2)$ versus $p(1)$ highlights the similarities and dissimilarities between descriptors and can be considered to be a sensory map of perfumery scents. This plot is obviously highly determined by the set of descriptors considered and, secondly, by the sample set itself. Therefore, it is important to compare the results to other similar plots derived from multivariate analyses of odor profiles. For this purpose, the scatterplot obtained here was visually compared to a similar 2D perfumery chart that resulted from applying PCA to the quantitative odor profiles of 309 aroma chemicals [30]. Those profiles were produced by six perfumers who assessed the compounds' similarities to 30 reference materials [31].

Next, stepwise regression models were fitted using the software Statgraphics 5.1 in order to predict $P_{\text {day }}$, seasonal percentages, $S_{\text {cool }}, P_{\text {like }}, P_{\text {dislike }}$, and $I_{F E M}$ as a function of all quantitative variables from FrD and the dichotomic ones (F-to-enter $=4, F$-to-remove $=4)$. The statistical significance ( $p$-value) of the regression coefficients was checked as well as the normal distribution of residuals in order to validate the resulting equations.

The number of feminine $\left(N_{F}\right)$ and masculine $\left(N_{M}\right)$ fragrances in the H\&R guide labeled with a given descriptor was computed. This guide is comprised of 453 women's and 367 men's perfumes, and hence the difference $\left(N_{F} / 453\right)-\left(N_{M} / 367\right)$ is positive for descriptors preferentially applied to feminine fragrances. As the frequency of occurrence is very different among descriptors, it seems convenient to take into account $\left(N_{F}+N_{M}\right)$, which leads to Equation (1). The exponent 0.3 appearing in the denominator is discussed in Section 3.10. This parameter was called "discriminating power according to gender" (DPG). Such values were compared to the PCA loadings.

$$
D P G=100 \frac{\left(N_{F} / 453\right)-\left(N_{M} / 367\right)}{\left(N_{F}+N_{M}\right)^{0.3}}
$$

\section{Results}

\subsection{Representativeness of the Perfume Set in the Market around the 1990s}

It turns out that 118 of Jellinek's perfumes $(67.8 \%)$ are targeted at women. This percentage was similar in different databases: FSP $(64.7 \%), \operatorname{EdG}(66.8 \%)$, and $\operatorname{FrD}(72 \%)$. Thus, the proportion of feminine and masculine perfumes used by Jellinek was representative of the market. Unisex fragrances were not considered to calculate these percentages. Only two of them are included in Jellinek's sample, which is too low. This issue is discussed below in Section 4.3.

Table 2 indicates the classification of Jellinek's fragrances according to the categories in the H\&R guide. As the percentages $P_{\text {Jelli }}$ and $P_{H E R}$ were similar, a chi-squared test was performed with the absolute frequencies (i.e., the number of occurrences $N_{\text {Jelli }}$ and $N_{H \mathcal{E}}$ ). Prior to this test, some related subcategories were summed in order to achieve a minimum occurrence of 5 . According to the results (test for women's data: $\chi^{2}(10)=3.7, p=0.9$; test for men's data: $\chi^{2}(7)=5.2, p=0.6$ ), the null hypothesis of independence could be assumed. The H\&R guide properly exemplifies the spectrum of fine fragrances sold in Europe around the 1990s. As the studies of Jellinek [1,27] were carried out at 
that time and taking into account the similar percentages shown in Table 2, Jellinek's sample can be regarded as representative of the fragrances in the German market in the early 1990s.

\subsection{Quantitative Odor Profiles from Fragrantica's Website}

Taking into account the similarities/dissimilarities between olfactory categories derived from the Fragrance Wheel [11] and other sensory maps [16,26,30], the classification of Jellinek's fragrances was compared according to the FrD, EdG [11], H\&R [3], FSP [7], and Groom's handbook [9]. Good agreement was found in most cases except for with 10 perfumes: 6 of them, targeted at women, are listed under the "mossy woods" category in EdG but are regarded as "flowery" by FrD and H\&R. This discrepancy is weird because "floral" and "mossy woods" appear as opposite classes in the Fragrance Wheel.

Next, for the subset of Jellinek's fragrances included in each category of EdG, the occurrence of descriptors compiled from FrD was checked. For example, 12 out of the 176 perfumes are listed in the "soft floral" class, and 9 of them (75\%) are rated as "aldehydic" in FrD (i.e., $X_{\text {aldehydic }}>0$ ). This class is the one with the highest occurrence of this descriptor, which is noteworthy because aldehydic notes are characteristic of soft floral fragrances [11]. Analogously, leather notes are typical of the dry-woods category, which yields the highest frequency of "leather" (63\%). The percentage of fragrances rated as $X_{\text {balsamic }}>0$ was computed, and the highest values corresponded with "oriental" (100\%), "soft oriental" $(86 \%)$, "woody-oriental" (81\%), and "floral-oriental" (47\%), which evidenced that oriental perfumes are characterized by balsamic ingredients [28]. Moreover, $X_{\text {balsamic }}$ yielded the highest correlation with $I_{\text {EDoriental }}\left(r_{163}=0.50, p<0.0001\right)$ and $I_{\text {HRsweet }}\left(r_{171}=0.43, p<0.0001\right)$.

Table 2. Classification of the 176 fragrances used by Jellinek [1,27] (118 women's, 56 men's, and 2 unisex) according to the H\&R categories [3]: number of fragrances listed under each category $\left(N_{\text {Jelli }}\right)$ and relative frequency as a percentage $\left(P_{\text {Jelli }}\right)$. The absolute frequency $\left(N_{H \in R}\right)$ and the relative frequency $\left(P_{H \& R}\right)$ of fragrances included in each category of the H\&R guide are also indicated.

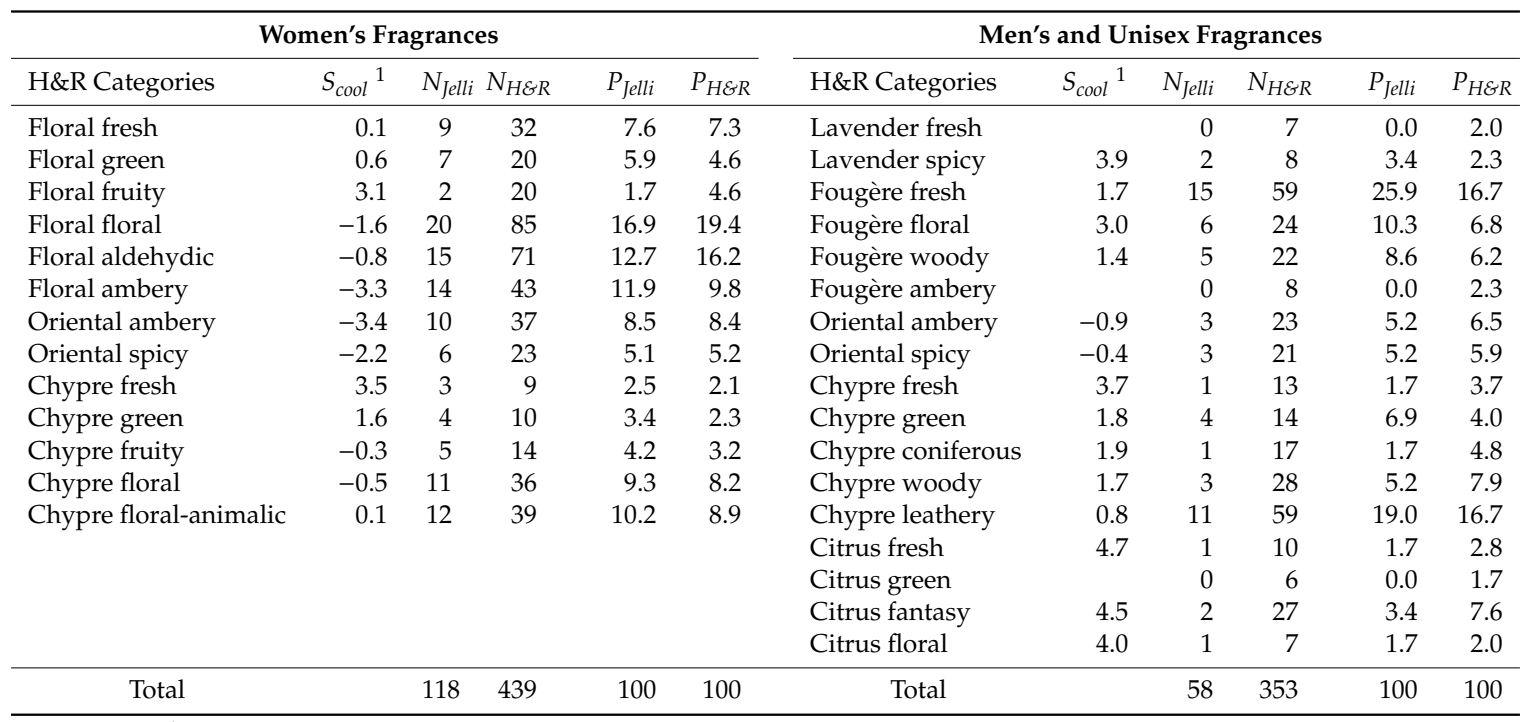

${ }^{1}$ Average cool score of the fragrances used by Jellinek [1,27] that are classified into each category.

\subsection{Dichotomic Matrix of Odor Profiles}

The absolute frequency of terms applied to describe perfumes in the H\&R guide is displayed in Table 3. The occurrence of each attribute in this guide for the description of Jellinek's perfumes is shown in Table 4 in order to allow for a comparison to Fragrantica's descriptors. The set of 16 variables $\left(I_{H R}\right)$ included in the dichotomic matrix (Table 1) is marked in Table 3 with an asterisk. Most had a direct correspondence with the 18 quantitative descriptors from the FrD (Table 4). 
Table 3. List of odor character descriptors used by H\&R [3] to describe the olfactory notes of 820 perfumes (453 women's and 367 men's). The table indicates the number of feminine $\left(N_{F}\right)$ and masculine $\left(N_{M}\right)$ fragrances in the H\&R guide labeled with a given term to describe either the top, middle, or base note.

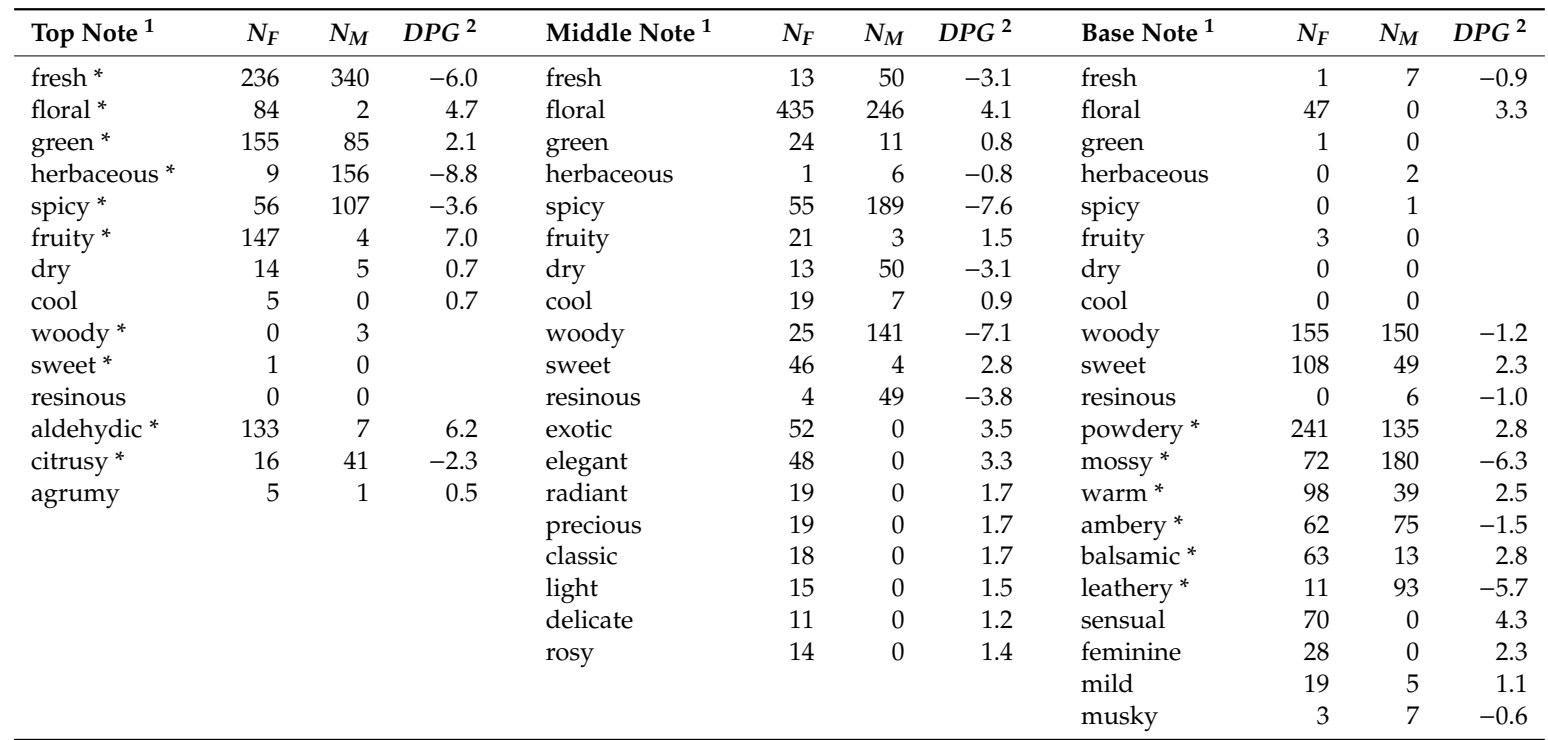

${ }^{1}$ The first 11 rows indicate descriptors often encountered in two phases (top, middle, or base), while the rest of the rows (12th-21st) correspond to terms only found in one phase. Descriptors with $\left(N_{F}+N_{M}\right)<5$ are not shown. Asterisks indicate the 16 relevant attributes applied to Jellinek's perfumes that were used in the multivariate analysis (Table 1: variables labeled as $I_{H R}$ ). ${ }^{2}$ Discriminating power according to gender (Equation (1)): positive values correspond to descriptors preferentially applied to women's fragrances, while the opposite applies to masculine ones.

"Woody" yielded the highest frequency in the FrD (Table 4: 150/176 = 85\%), followed by "floral" (63\%) and "aromatic" (50\%). Curiously, the latter was never encountered in the H\&R guide (Table 4). Instead of "aromatic", it seems that this guide used "fresh" and "herbal", which were more frequently applied than in the FrD. As discussed below, it is convenient to interpret "fresh" in the H\&R guide as "cool", which refers to the special refreshing/cooling effect of camphoraceous notes produced by the activation of trigeminal receptors.

"Ambery" is one category of the FSP guide that basically accounted for oriental fragrances, which was consistent with the fact that $X_{\text {amber }}$ yielded the strongest correlation with $X_{\text {balsamic }}\left(r_{171}=0.29\right.$, $p=0.0001)$ and $I_{\text {EDoriental }}\left(r_{163}=0.27\right)$. The current online version of the FSP guide has renamed this category as "ambery-oriental". This name seems more appropriate, because "amber" is applied to describe a scent that is warm, musky, rich, honey-like, and somewhat oriental, but not all oriental fragrances present marked musky notes. This association between "ambery", "balsamic", and "musk" would explain why the former was applied more frequently in the H\&R guide than in the FrD, while the opposite occurred with "balsamic" and "musk" (Table 4).

\subsection{Multivariate Analysis of Olfactory Profiles}

PC1, PC2, and PC3 explained 15.4\%, 13.3\%, and 7.4\%, respectively, of the data variability. These percentages were relatively low, which might lead to thinking about poor robustness because 2/3 of the information was not taken into account. However, comparable values have been obtained in similar studies (see Table 4 of Reference [30]). Analogously, the explained variance was 19\% and 11\% for PC1 and PC2, respectively, in another reported analysis of olfactory profiles [32]. Given the high dimensionality of odor perception space, several underlying constructs are usually required to explain a large portion of the data variability, even when accurate quantitative methods of odor description are used. 
Table 4. Absolute frequency (number of occurrences) for odor descriptors applied to the 176 perfumes in order to describe (a) the main accords according to Fragrantica's website $\left(N_{\operatorname{FrD}}\right)$ and (b) the top, middle, or base note according to the H\&R guide $\left(N_{H \& R}\right)$. Each descriptor is matched with the equivalent one (or most related) in the Boelens-Haring database [31].

\begin{tabular}{|c|c|c|c|c|c|}
\hline \multirow[b]{2}{*}{ Descriptor } & \multirow[b]{2}{*}{$N_{F r D}$} & \multirow[b]{2}{*}{$N_{H \mathcal{E}}$} & \multirow[b]{2}{*}{$p(2)^{1}$} & \multicolumn{2}{|c|}{ Boelens-Haring Database } \\
\hline & & & & Descriptor & $p(1)^{2}$ \\
\hline woody & 150 & 107 & -0.018 & woody & -0.124 \\
\hline floral & 111 & 158 & 0.186 & Floral & -0.010 \\
\hline aromatic & 88 & 0 & 0.027 & lavender-earthy & $0.060^{5}$ \\
\hline balsamic & 63 & 23 & -0.257 & balsamic & -0.249 \\
\hline fresh spicy & 59 & - & 0.076 & lavender-minty & $0.086^{5}$ \\
\hline green & 59 & 66 & 0.279 & green & 0.279 \\
\hline warm spicy & 59 & $68^{3}$ & -0.259 & spicy & -0.182 \\
\hline powdery & 58 & 65 & -0.074 & powdery & -0.323 \\
\hline earthy-mossy & 48 & 56 & -0.044 & earthy & -0.008 \\
\hline sweet & 45 & 38 & -0.156 & sweet & -0.280 \\
\hline citrus & 33 & 11 & 0.062 & citrusy & 0.189 \\
\hline animalic & 26 & $18^{4}$ & -0.116 & animal & -0.142 \\
\hline leather & 22 & 18 & -0.156 & animal-smoky & $-0.143^{5}$ \\
\hline aldehydic & 18 & 33 & 0.122 & aldehyde & 0.177 \\
\hline musky & 18 & 5 & -0.099 & & \\
\hline amber & 10 & 29 & -0.142 & erogenic & -0.161 \\
\hline herbal & 8 & 27 & 0.035 & vegetable & 0.126 \\
\hline fruity & 7 & 44 & -0.034 & fruity & 0.085 \\
\hline fresh 6 & 2 & 98 & & & \\
\hline
\end{tabular}

\footnotetext{
${ }^{1}$ Values from Figure 2 (vertical axis). ${ }^{2}$ PC1 loadings from the Boelens-Haring database (obtained from Figure 2 of Reference [30]). ${ }^{3}$ The value corresponds to "spicy". ${ }^{4}$ The value corresponds to "sensual". ${ }^{5}$ Mean value for the descriptors indicated, e.g., $p(1)_{\text {lavender-minty }}=\left[p(1)_{\text {lavender }}+p(1)_{\text {minty }}\right] / 2$. ${ }^{6}$ Fresh should be interpreted as "cool" (i.e., trigeminal refreshing-cooling effect).
}

I expected to find a certain correspondence between PC1 and PC2 with respect to $S_{\text {cool }}$ and $S_{\text {floral }}$, which are the consensus coordinates in Jellinek's maps. In order to study this issue, $t(1)$ and $t(2)$ scores were obtained with the software for all 176 perfumes, and next, multiple regression was applied to predict $t(1)$ as a function of $S_{\text {cool }}$ and $S_{\text {floral }}$ (Equation (2), $\left.R^{2}=0.52, n=176\right)$. The $p$-values of regression coefficients, which will be referred to as $p_{\mathrm{rc}}$, were low $\left(p_{\mathrm{rc}}<0.006\right)$, which indicated that the effect of both variables was statistically significant in Equation (2). A similar goodness-of-fit was obtained for $t(2)$ scores (Equation (3), $R^{2}=0.53, p_{\mathrm{rc}}<0.02$ ). The constant was not statistically significant (Equation (2): $p=0.4$; Equation (3): $p=0.5$ ) and it was removed from the models. Taking into account the absolute coefficients in both equations (0.14, similar to 0.12 , and 0.69 , similar to 0.61$)$, this result implied that PC1 and PC2 could be matched approximately to Jellinek's maps.

$$
\begin{gathered}
t(1)=-0.69 S_{\text {cool }}+0.14 S_{\text {floral }} \\
t(2)=0.12 S_{\text {cool }}+0.61 S_{\text {floral }}
\end{gathered}
$$

A visual inspection of the resulting PC1/PC2 loading plot (Figure S1) revealed the presence of an underlying latent structure (dashed line in red) determined by six variables (i.e., $P_{\text {day }}, P_{\text {night }}, P_{\text {spring }}$, $P_{\text {summer }}, P_{\text {fall }}$, and $\left.P_{\text {winter }}\right)$ that were strongly correlated, as discussed below. This factor exerted an excessive influence in the model because the degree of correlation among the rest of variables was much weaker. Hence, it seemed convenient to reduce the variance of this set of variables. For this purpose, a scaling coefficient of 0.7 was applied, and next, a new PCA was fitted.

It turned out that $p(1)$ loadings from the olfactory dataset compiled by Boelens and Haring [31], which will be referred to hereafter as the $\mathrm{BH}$ database, were correlated with the $p(2)$ loadings obtained here (values in Table 4: $r_{17}=0.81, p=0.0001$ ), which supported the equivalent interpretation of both 
dimensions. Furthermore, PC1 in the present study could be matched with PC2 of the BH database. In order to facilitate this comparison, Figure 2 shows the scatterplot of $p(2)$ versus $p(1)$ superimposed by the loading plot from the $\mathrm{BH}$ database $(p(1)$ vs. $p(2))$ by maintaining the same origin of coordinates (central point) and properly scaling the BH loadings so that "fresh" appeared close to $X_{\text {green }}$ and $P_{\text {day }}$. Flipping PC1 and PC2 to compare the most salient dimensions of these two olfactory databases might seem somewhat arbitrary, but related studies have reported that a similar amount of data variability was explained by the two principal underlying dimensions governing the perceptual space of perfumery scents; hence, PC1 and PC2 often appear swapped or rotated in analyses of olfactory profiles (e.g., Reference [30] (p. 241), References [32,33]).

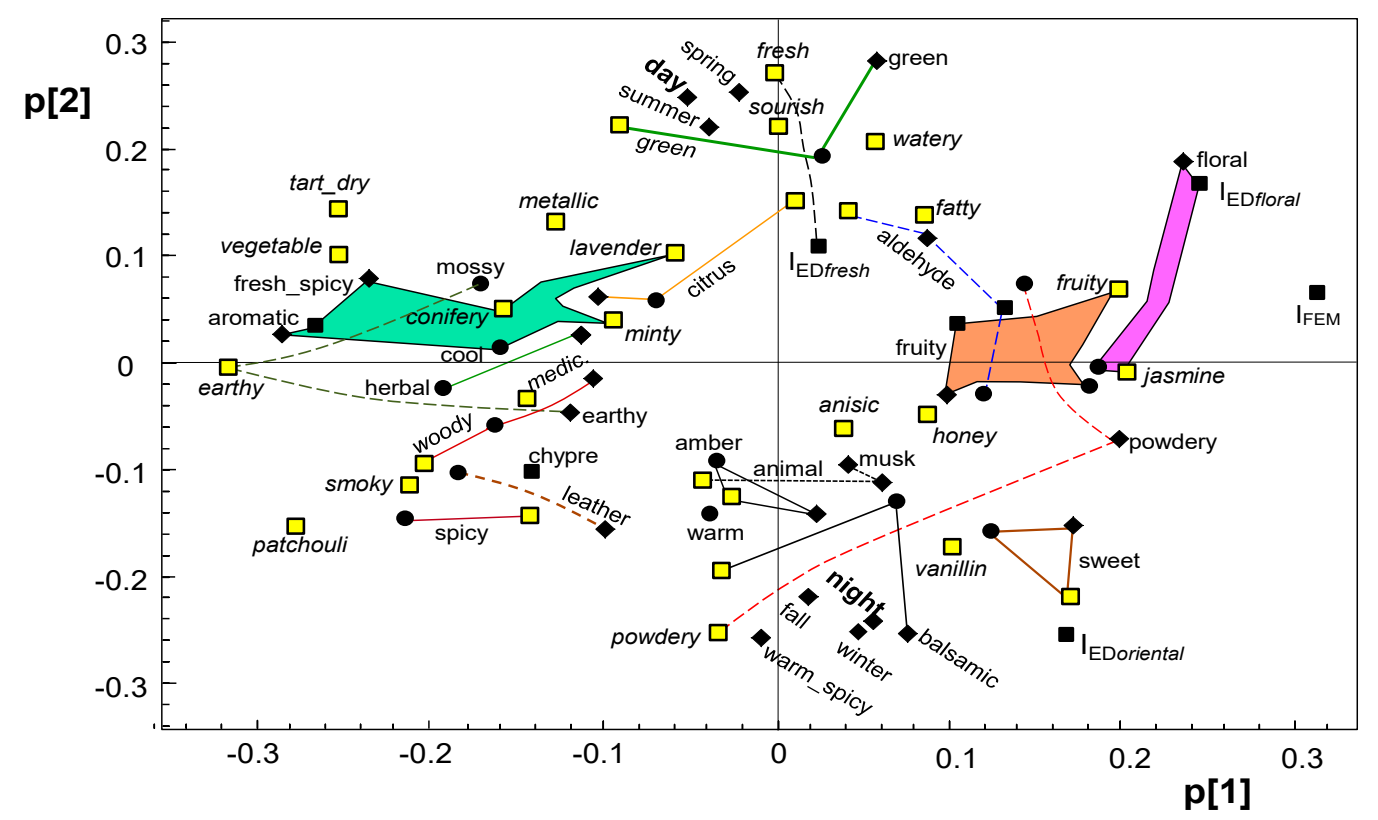

Figure 2. Loading plot ( $p(2)$ vs. $p(1)$ ) of the principal component analysis (PCA) applied to the olfactory profiles (48 variables) obtained for the 176 perfumes from Fragrantica and several perfume guides (see Table 1 for the lists of variables included and point codes). The loading plot ( $p(1)$ vs. $p(2)$ ) of the Boelens-Haring database [30] was superimposed (yellow squares; labels in italics) after being properly scaled. Equivalent descriptors are joined with lines. Fruity and floral scents (colored polygons) are the ones that are most typically feminine, while aromatic and related notes (green polygon) are commonly found in men's perfumes.

The resulting PC1/PC2 loading plot highlights the relationships between the variables. Two descriptors close to each other in this plot correspond to related odors (e.g., "balsamic" and "sweet"), and they presented a positive correlation (e.g., higher values of $X_{\text {balsamic }}$ were expected for perfumes rated as $I_{H R s w e e t}=1$ ). Conversely, two terms appearing on opposite sides, such as "aromatic" and "floral", are rarely found together in the description of a scent. Despite this general rule, it is not possible to quantify directly from Figure 2 the actual relationships between variables and their strengths. Pairs of descriptors with the highest positive correlations could have been indicated graphically, as was done in a previous work (see Figure 2 of Reference [30]), but the plot would have become very confusing. In this case, it is more important to highlight that olfactory variables from different sources referring to the same odor (e.g., $X_{\text {fruity }}, I_{H R f r u i t y}$, and $I_{\text {fruity }}$ ) appear close to each other in Figure 2. Such descriptors are joined with lines, and the legend "fruity" is indicated just once to avoid too many redundant legends inside the plot. $B H_{\text {earthy }}$ and $I_{H R m o s s y}$ were also linked because oakmoss was the reference material for the former in the $\mathrm{BH}$ database.

Regarding PC2, the highest loadings basically correspond to $P_{\text {day }}, P_{\text {summer }}, B H_{\text {fresh }}$, and $X_{\text {green }}$. Descriptors appearing on the opposite side are $P_{\text {night }}, P_{\text {winter }}, X_{\text {balsamic }}$, and $X_{\text {warm-spicy }}$. Thus, PC2 was mainly determined by these contrasting polarities: $P_{\text {day }}$ versus $P_{\text {night }}, P_{\text {summer }}$ versus $P_{\text {winter }}$, 
and "fresh-green" versus "warm-balsamic" scents. On the other hand, it turned out that IFEM was the variable with the highest $p(1)$ loading, which implied that the horizontal axis discriminated between women's and men's perfumes, as discussed in Section 3.10. All fruity variables were joined together, forming a polygon. Another one corresponded to "jasmine" and floral descriptors. Both polygons are colored to illustrate those notes most typically feminine. In contrast, the scents more frequently encountered in fragrances targeted at men appear on the opposite side. "Aromatic" and related descriptors (i.e., "fresh spicy", "conifery", "lavender", and "minty") are highlighted by means of a colored polygon to indicate that they refer to odors sharing camphoraceous notes that produce a special cooling effect, as further discussed below in Section 3.7.

It is noteworthy that "spicy" was approximately in the intermediate position of "warm-spicy" and "fresh-spicy". This loading plot was compared with the equivalent one from the BH database (yellow squares in Figure 2), and it turned out that the descriptor that disagreed the most was "powdery" (dashed line in red), probably because the reference material for this attribute smelled sweet-warm but not floral [30]. In contrast, $X_{\text {powdery }}$ yielded the strongest correlation with $I_{\text {EDoriental }}\left(r_{163}=0.33\right.$, $p<0.0001), I_{\text {HRsweet }}\left(r_{171}=0.27, p=0.0003\right)$, and $X_{\text {floral }}\left(r_{171}=0.26, p=0.0006\right)$, which justified the location of $X_{\text {powdery }}$ in Figure 2. This descriptor was basically encountered in the oriental categories: "soft oriental" (71\%), "oriental" (60\%), and "floral-oriental" (59\%). Regarding Xearthy, a position near that of $B H_{\text {earthy }}$ was expected, but it appeared closer to the center probably due to its correlation with $I_{\text {chypre }}\left(r_{171}=0.44, p<0.0001\right)$.

The software calculated the goodness-of-prediction through cross-validation $\left(Q^{2}\right)$ for each component. It was found that only PC1, PC2, and PC3 satisfied the cross-validation criterion because they had a positive $Q^{2}$ above the threshold limit considered by the software. The most interesting information provided by PC3, according to Figure 3, was that $I_{\text {chypre }}, X_{\text {woody }}$, and $X_{\text {earthy }}$ presented negative $p(3)$ loadings, while the opposite applied to $I_{\text {aromatic }}$. This result implies that "chypre" (woody-earthy scents) and "aromatic" account for well-defined different classes, despite $\mathrm{BH}_{\text {earthy }}$ and $\mathrm{I}_{\text {mossy }}$ being relatively close to the "aromatic" cluster colored in green in Figure 2 . Furthermore, the three variables accounting for "aldehydic" appeared with $p(3)<0$, while the opposite occurred with "sweet", "fruity", "citrus", and "floral". This result is appealing because "aldehyde" and "fruity" were basically coincident in their projection over the PC1/PC2 loading plot, but PC3 indicated that the smell of aldehydes was clearly distinct.

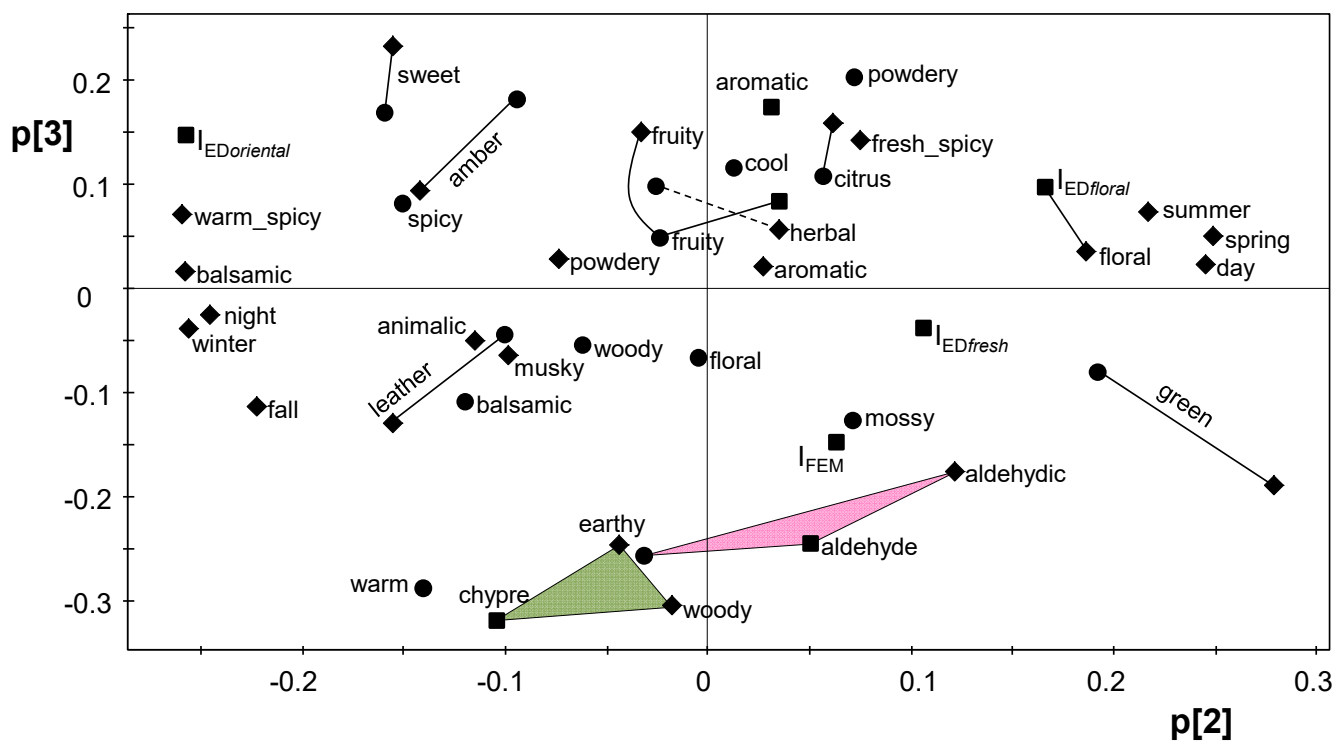

Figure 3. Loading plot ( $p(3)$ vs. $p(2))$ of the PCA applied to olfactory profiles (48 variables) obtained for the set of 176 perfumes (see Table 1 for list of variables included and point codes). Some equivalent odor descriptors are joined with lines. The green polygon highlights that "chypre" accounts for earthy-woody scents. 


\subsection{Daytime versus Nighttime and Seasonal Preference}

The warm character of oriental perfumes is such that they are mostly used as so-called winter or evening perfumes, as they are ideal for cool weather and formal nighttime wear $[1,28,34]$. Consistent with this association, $P_{\text {night }}$ was positively correlated with $P_{\text {fall }}\left(r_{171}=0.59, p<0.0001\right)$ and $P_{\text {winter }}$ $\left(r_{171}=0.85, p<0.0001\right)$, as shown in Figure 4a. Conversely, $P_{\text {night }}$ yielded a negative correlation with $P_{\text {spring }}\left(r_{171}=-0.77, p<0.0001\right)$ and $P_{\text {summer }}\left(r_{171}=-0.67, p<0.0001\right) . P_{\text {day }}$ was obviously associated with $P_{\text {summer }}\left(r_{171}=0.67, p<0.0001\right)$ and $P_{\text {spring }}\left(r_{171}=0.77, p<0.0001\right)$ because $P_{\text {day }}=100-P_{\text {night }}$, but the correlation became stronger $\left(r_{171}=0.83, p<0.0001\right)$ when considering the sum $P_{\text {summer }}+P_{\text {spring }}$, as displayed in Figure $4 \mathrm{~b}$.

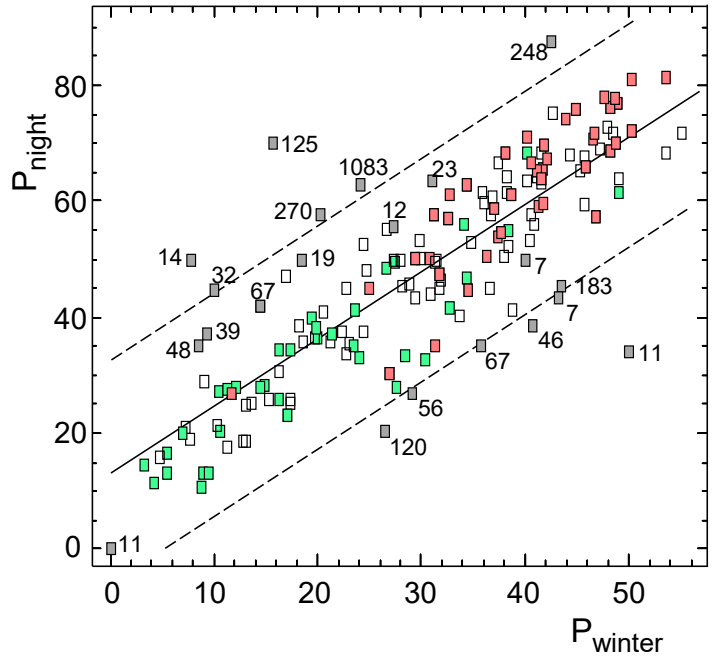

(a)

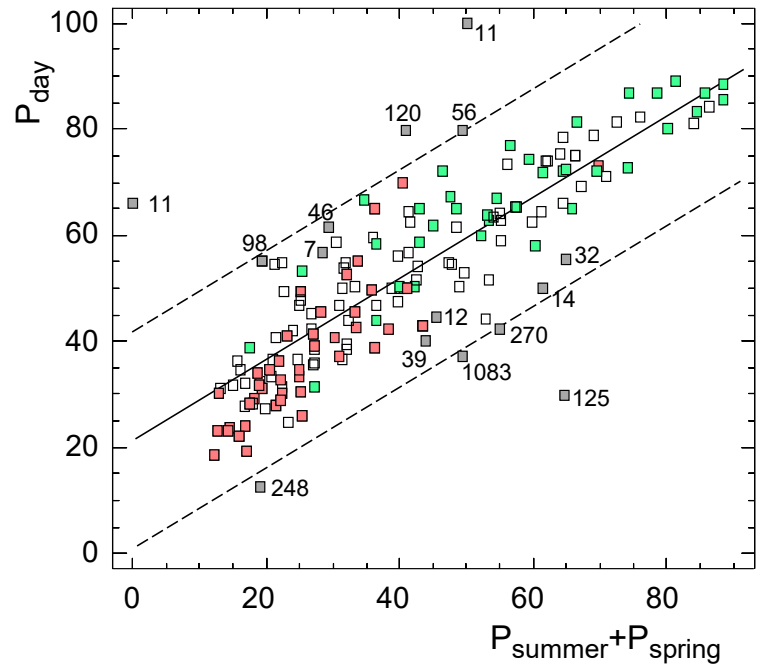

(b)

Figure 4. Consumer preferences obtained from Fragrantica's website for 176 perfumes. (a) Percentage of people who preferred the perfume for nighttime wear $\left(P_{\text {night }}\right)$ versus for wintertime $\left(P_{\text {winter }}\right)$; (b) percentage of consumers who preferred the perfume for daytime $\left(P_{\text {day }}\right)$ versus for summer $\left(P_{\text {summer }}\right)$ or spring $\left(P_{\text {spring }}\right)$. The fitted regression line is indicated. Dashed lines correspond to prediction limits with a confidence level of $95 \%$. Values next to each observation (points filled in gray) indicate the number of consumers who provided this information. Points filled in red: perfumes rated as $I_{\text {EDoriental }}=1$; in green: those with $\left(X_{\text {green }}+X_{\text {citrus }}\right)>3$.

The reliability of these percentages is uncertain. Actually, we do not know how consistent they are because anyone can vote online without any filter to guess if the person has actually tried the smell. When Fragrantica's website was created in 2007, some of Jellinek's perfumes were no longer available on the market; hence, the number of votes for them $\left(N_{\text {votes }}\right)$ was very small, and their accuracy remains doubtful. This hypothesis partly explains the presence of outlying observations that deviated from the linear trend in Figure 4 and appeared outside the 95\% prediction limits. Most of these outliers presented a relatively low value of $N_{\text {votes }}$, which implies that their percentages were not precise. On the basis of Figure 4 and some additional regression analyses that were carried out (results not shown), it seems that a minimum of around 70 votes is required to assume that the average information provided by consumers is trustworthy.

When only observations with $N_{\text {votes }}>70$ were considered $(n=143)$, the correlation coefficient became 0.90 and 0.88 in Figure 4a,b, respectively. Such relationships are well known in perfumery, but this is probably the first time that they have been quantified statistically. By using stepwise regression, it was found that musky perfumes increased the preference for nighttime wear (Equation (4), $R^{2}=0.85$, $p_{\text {rc }}<0.009$ ):

$$
P_{\text {night }}=8.7+1.28 P_{\text {winter }}+1.6 X_{\text {musky }}
$$




\subsection{Prediction of Daytime versus Nighttime Preference and Seasonal Preference}

By applying stepwise regression for observations with $N_{\text {votes }}>70$, Equation (5) was obtained to estimate $P_{\text {day }}\left(R^{2}=0.50, n=141, p_{\mathrm{rc}}<0.008\right)$. Seasonal percentages, $S_{\text {cool }}$, and $S_{\text {floral }}$ were not considered. Regarding the prediction of the four seasonal percentages, it was checked that they reasonably followed a normal distribution. These values were not reliable for observations with $N_{\text {votes }}<70$, and they were disregarded. The predictive equation for $P_{\text {winter }}\left(R^{2}=0.52, n=141, p_{\mathrm{rc}}<0.001\right)$ is not shown because variables entering into the model and their coefficients were nearly equivalent to Equation (5), which implied a tight association between $P_{\text {winter }}$ and $P_{\text {night }}$ (Figure 4a).

$$
P_{\text {day }}=53.9+4.2 X_{\text {green }}+2.7 X_{\text {citrus }}-11.0 I_{\text {EDoriental }}-7.9 I_{\text {HRwarm }}-2.2\left(X_{\text {balsamic }}+X_{\text {animalic }}\right)
$$

The resulting model for $P_{\text {summer }}$ was also basically the same (Equation (6), $R^{2}=0.39, n=141$, $\left.p_{\mathrm{rc}}<0.008\right)$. $X_{\text {animalic }}$ and $X_{\text {leather }}$ were summed given their similar coefficients and related odor. Animalic notes decrease the preference for summertime (Equation (6)) and daytime wear (Equations (4) and (5)), which is consistent with the experience of perfumers [26,35]. A similar model resulted for $P_{\text {spring }}$ (Equation (7), $\left.R^{2}=0.57, n=141, p_{\mathrm{rc}}<0.002\right)$. The main difference with respect to Equation (6) was the presence of $X_{\text {floral }}$, maybe because flowery scents are typical of spring. Consistent results were found in a reported 2D fragrance map [16] (p. 280) because "spring" appeared close to "floral", while "autumn" was mapped on the opposed side:

$$
\begin{gathered}
P_{\text {summer }}=24.4+1.5\left(X_{\text {green }}+X_{\text {citrus }}\right)-6.1 I_{\text {EDoriental }}-1.3 X_{\text {warm-spicy }}-1.5 X_{\text {woody }}-1.6\left(X_{\text {animalic }}+X_{\text {leather }}\right) \\
P_{\text {spring }}=20.4+2.9 X_{\text {green }}+1.5 X_{\text {citrus }}+1.7 X_{\text {floral }}-9.3 I_{\text {EDoriental }}-6.2 I_{\text {HRwarm }}-5.3 I_{\text {aldehyde }}
\end{gathered}
$$

Because of the negative correlation between $P_{\text {summer }}$ and $P_{\text {fall }}$, the model for the latter (Equation (8), $\left.R^{2}=0.43, n=141, p_{\mathrm{rc}}<0.0005\right)$ was equivalent to Equation (6). The foremost difference was the presence of $I_{\text {chypre }}$. Oakmoss smells mossy-woody and is the key ingredient in chypre fragrances [13], which justifies the name "mossy woods" (given by Edwards) [11]. Consistent with this criterion, $I_{\text {chypre }}$ yielded the highest correlation with $X_{\text {woody }}\left(r_{171}=0.44, p<0.0001\right)$ and $X_{\text {earthy }}\left(r_{171}=0.44, p<0.0001\right)$, which is intuitively appealing because mossy notes evoke freshly turned earth, forest soil, decaying leaves, roots, etc. (odors typically found in forests during autumn).

$$
P_{\text {fall }}=21.2-1.4 X_{\text {green }}+7.8 I_{\text {EDoriental }}+1.3\left(X_{\text {woody }}+X_{\text {leather }}\right)+3.2\left(I_{\text {chypre }}+I_{\text {aldehyde }}\right)
$$

The variable $I_{\text {aldehyde }}$ yielded a negative coefficient in Equation (7) but a positive one in Equation (8), which suggests that aldehydes recall autumn more than spring-like scents, maybe due to their slightly unpleasant character. Given the correlation between $P_{\text {day }}$ and seasonal percentages, the application of multivariate techniques such as Partial Least Squares (PLS) regression might seem more appropriate. It was checked that this method would lead to very similar results compared to stepwise multiple regression (for example, for the prediction of $P_{\text {summer }}\left(R^{2} Y=0.38\right)$ and $P_{\text {fall }}$ $\left.\left(R^{2} Y=0.43\right)\right)$. However, the interpretation of models and their comparisons, which was the main target of the predictive studies carried out here, was more straightforward using stepwise regression.

\subsection{Prediction of the Cool Odor Character}

Equation (9) was obtained to estimate $S_{\text {cool }}\left(R^{2}=0.52, n=163, p_{\mathrm{rc}}<0.006\right)$. $I_{\text {aromatic }}$ yielded the highest positive coefficient, which indicated that aromatic-fougère fragrances were mostly perceived as cool. The fougère accord, named after Fougère Royale by Houbigant (1882), is an abstract composition of lavender, oakmoss, and coumarin [3,13], justifying the presence of $I_{H R m o s s}$ in the model and its position close to "aromatic" in Figure 2. I aromatic yielded the highest correlation with $X_{\text {aromatic }}\left(r_{171}=0.59\right.$, $p<0.0001), I_{\text {HRherbaceous }}\left(r_{176}=0.55, p<0.0001\right)$, and $X_{\text {fresh-spicy }}\left(r_{171}=0.54, p<0.0001\right)$, which was in 
agreement with the herbaceous notes of lavender and coumarin [30]. All of Jellinek's perfumes that were classified as citrus or fougère-aromatic in EdG were rated as $X_{\text {aromatic }}>0$ in the FrD.

$$
S_{\text {cool }}=2.1 I_{\text {aromatic }}+1.1 I_{\text {HRmossy }}-1.6 I_{\text {EDoriental }}-1.2 I_{\text {HRsweet }}-0.43 X_{\text {animalic }}
$$

Lavender is probably responsible for the cool character of fougère accords due to its marked camphoraceous odor [36]. In nature, camphor-like notes are present in lavandin, rosemary, eucalyptus, sage, and conifer oils, among others [28]. The cooling effect of camphor and mentholic odors is apparent [37]. A reported analysis of the BH database found that PC4 is determined by "lavender", "minty", and "coniferous" [30], which share camphoraceous notes, producing a special cooling effect due to the activation of trigeminal receptors. The position of these descriptors and "aromatic" in Figure 2 is equivalent, as is "minty"/"camphoraceous" in the Odor Effect Diagram [35] and the aromatic-fougère category in Edwards's Wheel [11].

Fragrantica's descriptor "fresh-spicy" was applied to $86 \%$ of the perfumes classified as aromatic-fougère by EdG. Moreover, $X_{\text {aromatic }}$ yielded the strongest correlation with $X_{\text {fresh-spicy }}$ $\left(r_{171}=0.58, p<0.0001\right)$, which justifies the adjacent position of both variables in Figure 2 . The latter was correlated with $S_{\text {cool }}\left(r_{171}=0.4, p<0.0001\right)$ and $X_{\text {herbal }}\left(r_{171}=0.32, p<0.0001\right)$ but not with $X_{\text {green }}$ $\left(r_{171}=-0.10, p=0.2\right)$, which corroborates that "fresh-spicy" refers to cool-herbal scents. All spicy smells share a common pungency and sharpness [16] because tactile trigeminal receptors are involved (apart from the ordinary olfactory receptors that code for odor character). Eugenol smells warm and is often regarded as the reference for "spicy" [38], but "fresh-spicy" refers to herbs with a cool-camphoraceous character. Thus, "fresh-spicy" should be interpreted as "cool-spicy" for clarifying purposes. Similarly, $I_{\text {HRfresh }}$ yielded the highest correlation with $I_{\text {aromatic }}\left(r_{176}=0.30, p<0.0001\right)$, which suggests that it should be regarded as $I_{\text {HRcool }}$.

The odor map obtained by Richardson [33] associates green-citrus odors with "refreshing" and "invigorating", which is intuitively appealing because both terms are synonymous in English. The indicator variable $I_{E D \text { fresh }}$ yielded the highest correlation with $I_{\text {HRgreen }}\left(r_{162}=0.37, p<0.0001\right)$ and $X_{\text {green }}\left(r_{162}=0.26, p=0.0007\right)$, while the most negative correlation corresponded to $P_{\text {night }}\left(r_{162}=-0.13\right.$, $p=0.09$ ). This result agreed with the common interpretation of "fresh" in perfumery, as discussed below in Section 4.1 .

\subsection{Relationship between Cool, Oriental, and Winter Fragrances}

It turns out that $I_{\text {EDoriental }}$ yielded the highest correlation with $I_{\text {HRsweet }}\left(r_{163}=0.58, p<0.0001\right)$. Both presented a negative coefficient in Equation (9), which indicates that sweet-oriental odors were the ones most dissimilar to "cool". Actually, when checking the classification of Jellinek's fragrances in EdG and computing the average $S_{\text {cool }}$ for items within each category (Table 5), it turned out that the minimum values corresponded to "oriental" (-3.1), "floral-oriental" (-3.0), "soft oriental" (-2.4), and "woody-oriental" (-1.6). Oriental fragrances smell warm and sultry and contain ingredients that evoke images of the Far East, such as spices, musks (i.e., animalic notes), resins, exotic flowers, vanilla, sweet warm balsams, and powdery materials [34].

Given that oriental perfumes are preferred in winter, a tight negative correlation was expected between $S_{\text {cool }}$ and $P_{\text {winter }}$. Strikingly, this was not the case (Figure 5a), which further suggests that $S_{\text {cool }}$ refers to the specific trigeminal effect associated with camphoraceous odors. $P_{\text {winter }}$ is better explained by the distinction between warm fragrances (i.e., those with $t(2)<0$ ) with respect to daytime scents that are perceived as refreshing and invigorating (i.e., $t(2)>0$ ). This issue is illustrated in Figure 5a, which can be regarded as a sensory map of fragrances structured into four sections. Two of them are well defined: winter-warm oriental fragrances as opposed to the cool ones preferred for summertime. However, the section labeled "winter-cool" comprises both warm and refreshing perfumes. On the other hand, most non-cool fragrances for summertime smell refreshing, but not always. As the 
masculine or feminine character (i.e., targeted at men or women) is not reflected in Figure 5a, it seemed convenient to depict this information in another plot (Figure 5b).

Table 5. Number of fragrances ( $N_{F}$ : feminine, $N_{M}$ : masculine, $N_{U}$ : unisex) listed under each category of the directory compiled by Edwards in 2008 (24th edition) and a classification of the 163 perfumes used by Jellinek $[1,27]$ that are contained in this guide.

\begin{tabular}{|c|c|c|c|c|c|c|c|c|c|}
\hline \multirow{2}{*}{ Category } & \multicolumn{3}{|c|}{ Edwards's Guide } & \multicolumn{3}{|c|}{ Jellinek Perfumes } & \multicolumn{2}{|c|}{$N_{F}+N_{M}+N_{U}$} & \multirow{2}{*}{$S_{\text {cool }}{ }^{1}$} \\
\hline & $N_{F}$ & $N_{M}$ & $N_{U}$ & $N_{F}$ & $N_{M}$ & $N_{U}$ & Jellinek & Edwards & \\
\hline citrus & 146 & 138 & 167 & 2 & 3 & 1 & $6(3.7 \%)$ & $451(7.9 \%)$ & 4.3 \\
\hline green & 33 & 15 & 29 & 5 & 2 & 0 & $7(4.3 \%)$ & 77 (1.3\%) & 2.4 \\
\hline fruity & 21 & 0 & 3 & 0 & 0 & 0 & 0 & $24(0.4 \%)$ & \\
\hline water (marine) & 35 & 81 & 21 & 1 & 1 & 0 & $2(1.2 \%)$ & $137(2.4 \%)$ & 2.2 \\
\hline fougère aromatic & 8 & 572 & 21 & 0 & 20 & 1 & $21(12.9 \%)$ & $\begin{array}{r}601 \\
(10.5 \%)\end{array}$ & 2.1 \\
\hline woods & 71 & 263 & 63 & 0 & 4 & 0 & $4(2.5 \%)$ & $397(6.9 \%)$ & 1.8 \\
\hline mossy woods & 175 & 70 & 15 & 21 & 4 & 0 & $25(15.3 \%)$ & $260(4.5 \%)$ & 1.1 \\
\hline dry woods & 47 & 156 & 43 & 6 & 10 & 0 & $16(9.8 \%)$ & $246(4.3 \%)$ & 0.5 \\
\hline soft floral & 354 & 10 & 23 & 12 & 0 & 0 & $12(7.4 \%)$ & $387(6.8 \%)$ & -0.3 \\
\hline floral & 1446 & 17 & 44 & 24 & 1 & 0 & $25(15.3 \%)$ & $\begin{array}{r}1507 \\
(26.3 \%)\end{array}$ & -1.0 \\
\hline woody oriental & 352 & 361 & 65 & 10 & 6 & 0 & $16(9.8 \%)$ & $\begin{array}{r}778 \\
(13.6 \%)\end{array}$ & -1.6 \\
\hline soft oriental & 97 & 18 & 19 & 7 & 0 & 0 & $7(4.3 \%)$ & $134(2.3 \%)$ & -2.4 \\
\hline floral oriental & 533 & 1 & 6 & 17 & 0 & 0 & $17(10.4 \%)$ & $540(9.4 \%)$ & -3.0 \\
\hline oriental & 145 & 15 & 31 & 4 & 1 & 0 & $5(3.1 \%)$ & $191(3.3 \%)$ & -3.1 \\
\hline Total & 3463 & 1717 & 550 & 109 & 52 & 2 & $163(100 \%)$ & $\begin{array}{r}5730 \\
(100 \%)\end{array}$ & \\
\hline
\end{tabular}

${ }^{1}$ Average cool score of the fragrances used by Jellinek $[1,27]$ that are classified into each category. Rows in the table are sorted by decreasing order of this value.

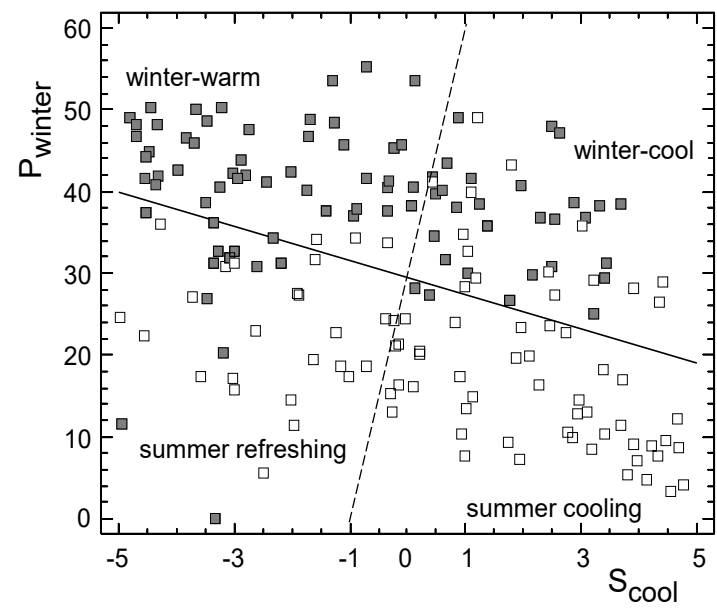

(a)

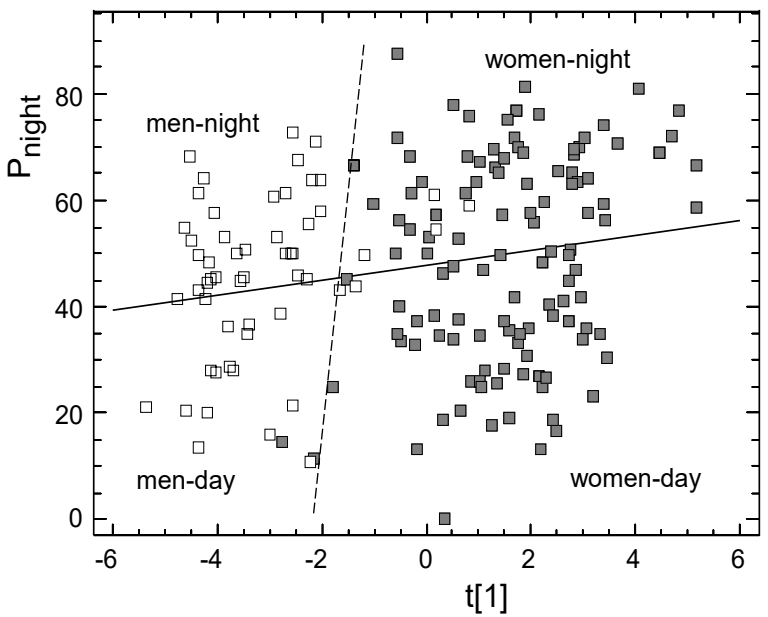

(b)

Figure 5. Sensory maps of 176 fragrances. Dashed lines were drawn to divide the scatterplot into four meaningful sections. (a) Fitted linear regression between winter preference $\left(P_{\text {winter }}\right)$ versus cool odor character $\left(S_{\text {cool }}\right)$. Filled points: $t(2)<0$ (i.e., warm perfumes); (b) plot of fitted linear regression between preference for nighttime wear $\left(P_{\text {night }}\right)$ versus $t(1)$ scores obtained from the final PCA. Filled points: women's fragrances.

\subsection{Regression Models about "Like" versus "Dislike"}

The percentages for "like", "love", or "dislike" provided by FrD are presumably not reliable for observations with $N_{\text {votes }}<70$, and they were discarded. It was found that $P_{\text {like }}$ yielded the highest correlation with $P_{\text {day }}\left(r_{143}=0.50, p<0.0001\right), P_{\text {summer }}\left(r_{143}=0.41, p<0.0001\right), X_{\text {fresh-spicy }}\left(r_{143}=0.29\right.$, $p=0.0004)$, and $I_{E D f l o r a l}\left(r_{141}=0.18, p=0.03\right)$. These variables were reflected in the resulting model (Equation (10), $R^{2}=0.32, n=141, p_{\mathrm{rc}}<0.01$ ), which was consistent with the fact that fragrances are 
more frequently used for daytime wear. Moreover, aromatic-fougère is the category in EdG comprising the highest percentage of men's fragrances, while floral scents are typically feminine. Similar results were expected for "like" and "love" because they are analogous concepts; however, $P_{\text {love }}$ was positively correlated with $P_{\text {night }}\left(r_{143}=0.27, p=0.001\right)$ and $P_{\text {winter }}\left(r_{143}=0.20, p=0.02\right)$. Given the trouble in interpreting these associations, the predictive equation for $P_{\text {love }}\left(R^{2}=0.19\right)$ was omitted.

$$
P_{\text {like }}=27.0+0.18 P_{\text {day }}+4.8 I_{\text {aromatic }}+3.3 I_{\text {EDfloral }}
$$

The model obtained for $P_{\text {dislike }}$ (Equation (11), $R^{2}=0.11, n=143, p_{\mathrm{rc}}<0.009$ ) presented a low goodness-of-fit, which suggests that fragrances are formulated in ways that try to avoid unpleasant notes that are generally disliked. The negative coefficients of $X_{\text {fresh-spicy }}$ and $X_{\text {green }}$ in Equation (11) revealed that refreshing fragrances for daytime wear tend to be liked/loved more than warm odors, which justifies the fact that they are used more often.

$$
P_{\text {dislike }}=100-P_{\text {like }}-P_{\text {love }}=20.4-1.4 X_{\text {fresh-spicy }}-1.1 X_{\text {green }}
$$

\subsection{Classification of Perfumes as Men's versus Women's}

Regarding $I_{F E M}$, it could be predicted with a reasonable goodness-of-fit (Equation (12), $R^{2}=0.77$, $\left.n=141, p_{\mathrm{rc}}<0.003\right)$. When all regression coefficients in Equation (12) are null, $I_{F E M}$ becomes 0.74 , which is close to the rate of feminine perfumes in the $\operatorname{FrD}(72 \%)$. Therefore, $I_{F E M}$ could be interpreted as the probability of a given fragrance being targeted at women. The two main discriminating variables were $S_{\text {floral }}$ and $I_{\text {aromatic }}$, followed by $I_{\text {HRleathery }}$ and $I_{\text {HRaldehyde. }}$. It turned out that $S_{\text {floral }}$ yielded the highest correlation with $X_{\text {floral }}\left(r_{171}=0.69, p<0.0001\right)$ and $I_{E D \text { floral }}\left(r_{163}=0.63, p<0.0001\right)$, which makes sense.

$$
I_{F E M}=0.74+0.064 S_{\text {floral }}+0.16 I_{\text {HRaldehydic }}+0.13 I_{\text {EDoriental }}-0.47 I_{\text {aromatic }}-0.35 I_{\text {HRleathery }}
$$

The regression coefficients of descriptors included in Equation (12) reveal their feminine or masculine character. For the remaining terms not appearing in this model, the following study was carried out. As explained in Section 2.5, descriptors preferentially applied to feminine rather than masculine fragrances are those with a positive value of the difference $D_{F-M}=\left(N_{F} / 453\right)-\left(N_{M} / 367\right)$. The value $D_{F-M}$ was very similar for, e.g., "warm" and "elegant", but the latter presented a higher power to discriminate between feminine and masculine fragrances because it was only encountered in women's perfumes (Table 3). Hence, this discriminative power needed to be decreased for "warm". Given that it was applied more often than "elegant", according to $N_{F}+N_{M}$, it seems convenient to introduce some kind of nonlinear correction taking into account this sum. On the basis of this idea, a parameter called "discriminating power according to gender" (DPG) was computed (Equation (1)). The exponent 0.3 in this equation was obtained as follows. First, this exponent $(k)$ was set to 1 , and DPG values were calculated for all descriptors. Next, using an Excel spreadsheet, a discriminant function $(D)$ was computed as a linear combination of all variables, using DPG values as weight coefficients. Finally, using the optimization tool Solver of Excel, it turned out that $k=0.3$ was the optimum value so that the correlation between $D$ and $I_{F E M}$ was maximized. Thus, DPG values (Table 3) can be regarded as coefficients of a discriminating function in order to estimate if a given perfume should be targeted at men or women.

\section{Discussion}

\subsection{Interpretation of Daytime versus Nighttime Preference}

Refreshing perfumes are preferred for informal daytime wear, while the opposite applies to warm scents [1]. Such polarity is reflected by the vertical axis of Figure 2. Perfumers find it difficult to explain the exact meaning of "fresh" when describing a scent [39]. This term is usually applied to invigorating odors such as the clean scent of early morning air, which is reminiscent of the outdoors 
(i.e., nature-inspired) and is typified by the green note of recently cut leaves, citrus notes, or perhaps ozonic smells [16]. In perfumery, "green" refers to the smell of cut grass or leaves [13]. Green is the most typical color of nature, and curiously, fresh odors are associated with a leafy-green color [40,41], which supports the hypothesis that fresh odors evoke natural environments.

Conversely, balsamic/oriental fragrances smell warm, which is the odor character most dissimilar to "fresh" in the BH database [30]. The reason might be that "fresh" in French (frais) means moderately cool [26]. Interestingly, the regression coefficients of $X_{\text {green }}$ and $X_{\text {citrus }}$ in Equations (5)-(7) were positive, while the opposite applies to descriptors referring to warm odors. Thus, Equation (5) suggests that $P_{\text {day }}$ can be regarded as an indirect estimation of the "fresh" character of a perfume. The same interpretation was derived from a reported 2D fragrance map [16] (p. 279) because "morning" was located very close to "fresh" while "night" appeared on the opposite side.

A sensory study conducted on 600 people using 21 fragrances found that extroverted subjects who described themselves as searching for stimulation preferred fresh perfumes and associated them with "active", "clear", "green", and "yellow". Conversely, introverted subjects preferred oriental fragrances [42]. Similar results were found by applying PCA to quantitative odor profiles comprised by 55 attributes that were rated for 37 aroma chemicals [43]. Descriptors with higher loadings in PC2 were "sour", "cold", and "clear", which suggested the interpretation of this factor as "fresh"; conversely, "warm" and "sweet" yielded opposite loadings. An association between "clear", "cool", and "sour" was also found in a reported analysis of numeric profiles obtained for 11 odorants according to 30 descriptors [44]. Fresh fragrances, which are preferred for daytime wear (Equation (5)), seem to evoke clear environments, probably because daylight conditions are obviously associated with clarity.

The similarity between sourish, green, and fresh odors is well known [30], as is their dissimilarity to warm scents. According to some experts, "cool" is a vague descriptor without any precise definition in perfumery [16]; nonetheless, the results reported here reveal that "cool" should be applied to the trigeminal effect produced by herbal/spicy odors with camphoraceous notes.

\subsection{Interpretation of the Masculine versus Feminine Polarity}

The horizontal axis of Figure 2 (PC1) can be interpreted as a factor that discriminates between fragrances targeted at men versus women because $I_{F E M}$ yielded the highest $p(1)$; moreover, $D P G$ values and $p(1)$ loadings were strongly correlated. Descriptors with the highest DPG were "floral", "fruity", "aldehydic", "sweet", "powdery", and "balsamic" (Table 3), which was in good agreement with Equation (12) (taking into account that $I_{E D o r i e n t a l}$ yielded the highest correlation with $I_{H R s w e e t}$ $\left(r_{163}=0.58, p<0.0001\right)$ and $\left.X_{\text {balsamic }}\left(r_{163}=0.50, p<0.0001\right)\right)$. Conversely, the five most negative DPG values corresponded to "herbaceous", "spicy", "woody", "mossy", and "fresh". The fougère accord properly exemplified most of these masculine descriptors, as was discussed in Sections 3.3 and 3.7, which is consistent with the presence of $I_{\text {aromatic }}$ in Equation (12). This model also included "leathery", which was the descriptor with the sixth most negative value of DPG.

The results were consistent with the experience of perfumers, because masculine fragrances are generally less floral and often contain dry notes of leather, tobacco, herbs, spices, mosses, and woods [28]. "Dry" is applied to describe the lack of sweetness in perfumery [16]. A reported study has used Fragrantica's information to predict experimental femininity ratings, but only 12 fragrances were used [45]. In contrast, Equation (12) and the values in Table 3 provide more accurate information about the scents more typically found in men's versus women's fragrances.

\subsection{Representativeness of the Perfume Set According to the Modern Market}

The results reported here are obviously constrained by the sample analyzed, which corresponded to quite old perfumes. Table 5 shows the number of items listed under each class of the directory published by Edwards in 2008, as well as how many of Jellinek's perfumes were found in each category of this guide. Only two of them were unisex (1.2\%), which was much lower than the percentage of unisex fragrances in 2008 (9.6\%). As demand for them has increased considerably since the 1990s, 
unisex perfumes were not properly represented in the sample. Nevertheless, they do not account for a particular olfactory class: about one-third of them are classified as citrus, which has a reasonable correspondence with the Fragrance Wheel (Figure 6).

A subset of oriental scents called "gourmand" (designed to smell distinctly dessert-like with an emphasis on caramel and vanilla) has become popular in recent years [13] (p. 571). This new trend, which was pioneered by Angel (1992) by Thierry Mugler, was not properly represented in Jellinek's perfumes. Another recent trend, particularly in Middle Eastern markets, is based on a raw ingredient called oudh or agarwood, which has a scent described as musky, musty, and woody-nutty.

In order to further discuss the relevance of the results reported here to the actual market, a chi-squared test was carried out to compare the number of occurrences in the sample of Jellinek's perfumes based on the EdG classification. The test was applied for the total number of items under each category (i.e., $N_{F}+N_{M}+N_{U}$ in Table 5) because this test requires an occurrence $\geq 4$. Prior to the test, "citrus", "green", "fruity", and "water" classes were summed together to achieve this condition.

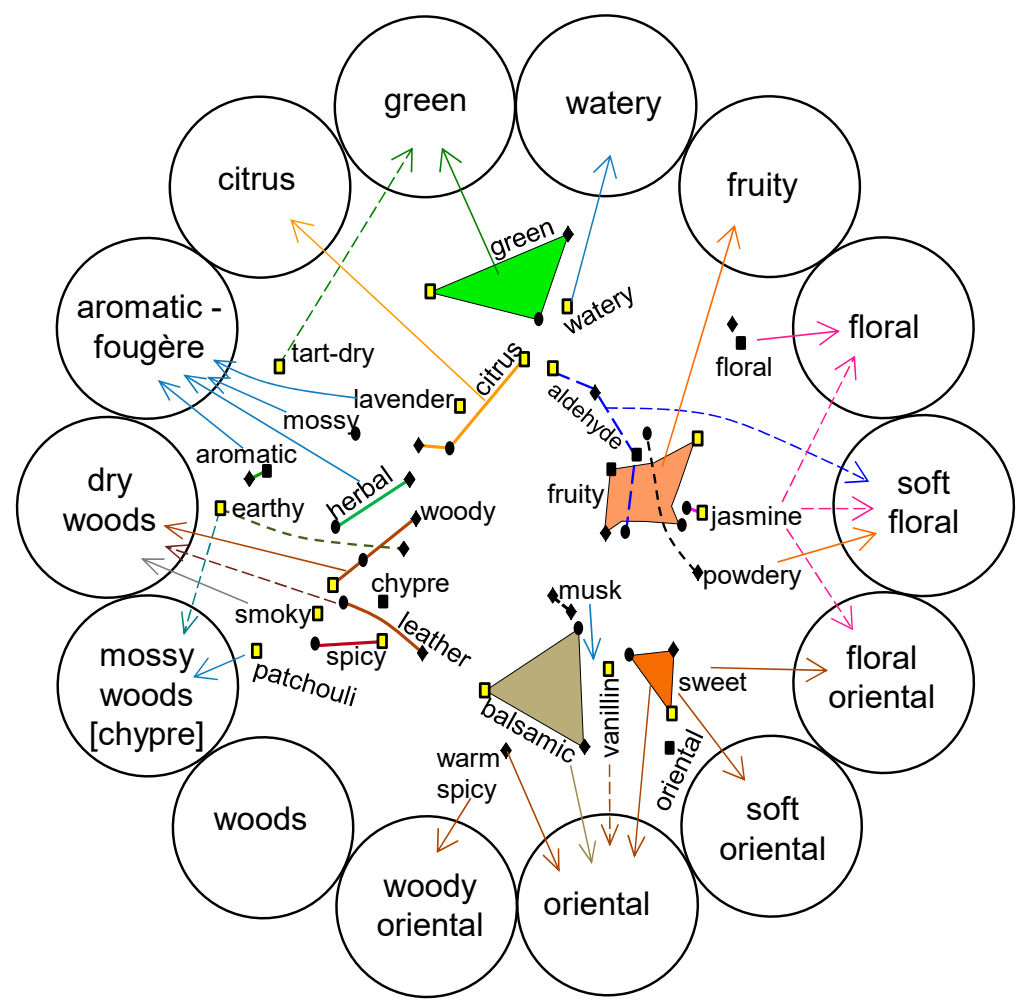

Figure 6. The Fragrance Wheel (perfume categories displayed within circles). The sequence around the central hub is the same as that proposed by Edwards [11] (except for "green" and "watery", which were swapped). The Wheel was properly rotated to achieve the maximum correspondence with related studies $[26,30]$ as well as with Figure 2, which is also depicted inside (some descriptors were removed for clarity purposes). Arrows indicate the most typical notes of each olfactory class.

The null hypothesis of independence was rejected $\left(\chi^{2}(10)=67.5, p<0.0001\right)$ because the sample contained an excessive proportion of "mossy woods" fragrances (Table 5). The same conclusion was obtained by repeating the test after discarding this category $\left(\chi^{2}(9)=30.6, p=0.0003\right)$ due to an excessive rate of "dry woods" items. If this class is disregarded $\left(\chi^{2}(8)=16.6, p=0.03\right)$, it turns out that the number of soft oriental perfumes in the sample was slightly large. In summary, the results of this chi-squared test suggested that none of the fragrance classes were underrepresented in the sample. Although the market of fragrances has evolved since the 1990s, Figure 6 shows that the sensory map of odor descriptors is consistent with the Fragrance Wheel, which suggests that the sample studied here properly exemplifies the perceptual spectrum of fragrances. 


\section{Conclusions}

With thousands of perfumes currently available, shopping for a new fragrance is a complex task for consumers. The development of 2D sensory maps of commercial fragrances is of relevant interest as a tool to aid in the communication between retailers and consumers. The loading plot obtained here (Figure 2) had good agreement with the maps reported by Jellinek [1,27] as well as with the Odor Effect Diagram [35], the Fragrance Wheel [11], a sensory chart of toilet-soap bars [33], and other 2D maps of odor descriptors $[16,30,32]$. Hence, the underlying dimensions can be interpreted analogously.

In order to make sensory maps easy to understand, some of them are designed in the shape of a wheel, displaying several olfactory categories around a central hub. Several sensory wheels have been developed for perfumery descriptions, such as the Discodor [24], the Hexagon of Fragrance Families [17], and the Drom Fragrance Circle [25]. The Fragrance Wheel [11] is probably the most famous and trusted in the industry. First proposed in 1984, it was basically derived from the experience of Edwards and was not based on sensory experiments. In its first versions, the category "aromatic-fougère" was located at the center. However, on the basis of research by Zarzo and Stanton [30], this class was inserted between "citrus" and "dry woods" in the 26th edition in 2010 [11]. The results reported here (Figure 6) provide further scientific evidence supporting the current version of the Fragrance Wheel as a valuable tool for fragrance classification.

The olfactory categories "green" and "watery" in Figure 6 were swapped compared to Edwards's Wheel in order to achieve a better fit with the sensory map of odor descriptors. The position of "tart (dry)", which was relatively close to the "green" category, makes sense because galbanum resinoid is the reference material for this descriptor in the $\mathrm{BH}$ database, and it is encountered in many fragrances classified as "green" [11]. As discussed above, "aromatic-fougère" is a blend of lavender, oakmoss, and coumarin $[3,13]$ : the latter smells herbaceous, which justifies the proximity of "herbal" to this class. Regarding "dry woods", which is often called "leather", it is intuitively appealing that "woody", "smoky", and "leather" appear close to each other, because this class is determined by cedarwood, tobacco, and leathery notes that resemble the smoky scent of Russian leather [11]. Chypre fragrances (mossy woods) are characterized by the contrast between a citrus accord and the forest notes of oakmoss. The position of "patchouli" next to "mossy woods" is consistent with the woody-earthy smell of this material.

Oriental perfumes are exotic, opulent, and warm, containing musks and sweet spicy odors such as cinnamon and vanilla. The position of odor descriptors in Figure 6 is consistent with the typical scents of this odor class. Soft-oriental perfumes are not as sweet as the true oriental ones, which are mainly based on flowers and warm spices. The floral-oriental category moves toward floral scents, which are subtly spicy and are blended with notes of amber, aldehydes, or fruits. Finally, soft-floral fragrances are characterized by sparkling aldehydes and delicate flowers, creating a family of soft abstract florals that are often powdery [11]. In summary, the odor descriptors that are nearest to each category of the Fragrance Wheel have a reasonable correspondence with the most typical notes encountered in each class.

The results reported here were consistent with previous studies suggesting that 2D sensory odor maps only account for about $25 \%-30 \%$ of data variability (if smells are described by means of quantitative odor profiles). Human olfactory perception space is highly dimensional, and hence odor descriptors are rather independent, which is in agreement with the relatively low amount of variance explained by the principal components. The present work does not intend to overemphasize the usefulness of the Fragrance Wheel or other 2D odor maps, taking into account the large amount of variation that is not explained using just two factors. Nonetheless, the multivariate analysis of fragrance descriptions led to two meaningful dimensions that had a direct correspondence with the classification of commercial perfumes as men's versus women's or as a preference for daytime versus nighttime wear. Both polarities should be considered to reach a certain consensus about how to plot fragrances on a sensory 2D map, which would be useful to visually illustrate relationships with other fragrances. This is an alternative approach to traditional classification into well-defined categories. 
Supplementary Materials: The following are available online at http://www.mdpi.com/2079-9284/7/1/3/s1, Figure S1: Loading plot of the PCA applied to olfactory profiles from Fragrantica's website and the H\&R guide for the 176 perfumes.

Funding: This research received no external funding.

Acknowledgments: I am grateful to C. Quintero for a preliminary statistical analysis of the olfactory qualities of the 176 perfumes studied in this work.

Conflicts of Interest: The author declares no conflict of interest.

\section{References}

1. Jellinek, J.S. Perfume classification: A new approach. In Fragrance: The Psychology and Biology of Perfume; Van Toller, S., Dodd, G.H., Eds.; Chapman \& Hall: London, UK, 1992; pp. 229-242.

2. Wörner, P. Genealogy of Perfumes, 2nd ed.; Wörner, P., Ed.; Haarmann \& Reimer: Holzminden, Germany, 1978.

3. Glöss, W. HER Fragrance Guide: Feminine and Masculine Notes, 2nd ed.; Glöss, W., Ed.; Glöss Verlag: Hamburg, Germany, 1991.

4. Haarmann \& Reimer. The HER Genealogy: Feminine Fragrances, 11th ed.; H\&R: Holzminden, Germany, 2002; Available online: http://www.leffingwell.com/h\&rfragrance/poster_genealogie_feminin.pdf (accessed on 10 December 2019).

5. Symrise Fragrances Genealogy 2015, 23rd ed.; Symrise AG: Holzminden, Germany, 2015; Available online: http://symrisegenealogy.com (accessed on 28 January 2016).

6. Eurofragrance 2011: Feminine Fragrances Genealogy. Available online: http://www.eurofragance.com/docs/ 26_2011_fem_geneology_eurofragance.jpg (accessed on 10 September 2015).

7. Société Française des Parfumeurs. La Classification des Parfums, 3rd ed.; Comité Français du Parfum: Paris, France, 1998.

8. Olfactive Families of Fragrances According to the French Society of Perfumers. Available online: https: //www.parfumeurs-createurs.org/fr/filiere-parfum/les-familles-olfactives-102 (accessed on 10 June 2019).

9. Groom, N. The New Perfume Handbook, 2nd ed.; Blackie Academic \& Professional: London, UK, 1997.

10. Edwards, M. The Fragrance Manual, 1st ed.; Crescent House Publishing: La Quinta, CA, USA, 1984.

11. Edwards, M. Fragrances of the World: Parfums du Monde 2010, 26th ed.; Fragrances of the World: Sydney, BC, Canada, 2010.

12. Osmoz Website for Olfactory Exploration of Men's and Women's Commercial Fragrances. Available online: http://www.osmoz.com/perfumes/search (accessed on 10 September 2015).

13. Turin, L.; Sanchez, T. Perfumes: The A-Z Guide; Penguin Books: New York, NY, USA, 2009.

14. Jaubert, J.N.; Tapiero, C.; Doré, J.C. The field of odors: Toward a universal language for odor relationships. Perfum. Flavorist 1995, 20, 1-16.

15. Chastrette, M.; de Saint Laumer, J.Y.; Sauvegrain, P. Analysis of a system of description of odors by means of four different multivariate statistical methods. Chem. Senses 1991, 16, 81-93. [CrossRef]

16. Thiboud, M. Empirical classification of odors. In Perfumes: Art, Science and Technology; Müller, P.M., Lamparsky, D., Eds.; Elsevier: New York, NY, USA, 1991; pp. 253-286.

17. Haldiman, R.F.; Schuenemann, T. The hexagon of fragrance families. Dragoco Rep. 1990, 37, 83-89.

18. Milotic, D. The impact of fragrance on consumer choice. J. Consum. Behav. 2003, 3, 179-191. [CrossRef]

19. Cadoret, M.; Lê, S.; Pagès, J. A factorial approach for sorting task data (FAST). Food Qual. Prefer. 2009, 20, 410-417. [CrossRef]

20. Veramendi, M.; Herencia, P.; Ares, G. Perfume odor categorization: To what extent trained assessors and consumers agree? J. Sens. Stud. 2013, 28, 76-89. [CrossRef]

21. Kostov, B.; Bécue-Bertaut, M.; Husson, F. An original methodology for the analysis and interpretation of word-count based methods: Multiple factor analysis for contingency tables complemented by consensual words. Food Qual. Prefer. 2014, 32, 35-40. [CrossRef]

22. Teixeira, M.A.; Rodríguez, O.; Rodrigues, A.E. Perfumery radar: A predictive tool for perfume family classification. Ind. Eng. Chem. Res. 2010, 49, 11764-11777. [CrossRef]

23. Teixeira, M.A.; Barrault, L.; Rodríguez, O.; Carvalho, C.C.; Rodrigues, A.E. Perfumery radar 2.0: A step toward fragrance design and classification. Ind. Eng. Chem. Res. 2014, 53, 8890-8912. [CrossRef] 
24. Harder, U. Der H\&R duftkreis. Haarman Reimer Contact 1979, 23, 18-27, An Updated Version in English. Available online: http://www.leffingwell.com/h\&rfragrance/Fragrance\%20Families.pdf (accessed on 10 December 2019).

25. Jasper, A.; Wagner, N. Notes on Scent. Cabinet. 2008. Available online: http://cabinetmagazine.org/issues/32/ jasper_wagner.php (accessed on 10 December 2019).

26. Zarzo, M. What is a fresh scent in perfumery? Perceptual freshness is correlated with substantivity. Sensors 2013, 13, 463-483. [CrossRef] [PubMed]

27. Jellinek, J.S. A consumer oriented classification of perfumes. Dragoco Rep. 1990, 37, 16-29.

28. Müller, J. The HER Book of Perfume: Understanding Fragrance; Origins, History, Development: Guide to Fragrance Ingredients; Glöss Verlag: Hamburg, Germany, 1992.

29. Green, M. Natural Perfumes: Simple Aromatherapy Recipes; Interweave Press: Loveland, CO, USA, 1999.

30. Zarzo, M.; Stanton, D.T. Understanding the underlying dimensions in perfumers' odor perception space as a basis for developing meaningful odor maps. Atten. Percept. Psychophys. 2009, 71, 225-247. [CrossRef] [PubMed]

31. Boelens, H.; Haring, H.G. Molecular Structure and Olfactive Quality; Naarden International (internal report): Bussum, The Netherlands, 1981.

32. Zarzo, M. Underlying dimensions in the descriptive space of perfumery odors: Part II. Food Qual. Prefer. 2015, 43, 79-87. [CrossRef]

33. Richardson, A. Measurement of fragrance perception. In The Chemistry of Fragrances; Pybus, D.H., Sell, C.S., Eds.; The Royal Society of Chemistry: Cambridge, UK, 1999; pp. 145-157.

34. Moran, J. Fabulous Fragrances II: A Guide to Prestige Perfumes for Women and Men; Crescent House Publishing: La Quinta, CA, USA, 2000.

35. Jellinek, P. Die Psychologischen Grundlagen der Parfümerie; Alfred Hüthig Verlag: Heidelberg, Germany, 1951.

36. Dove, R. The Essence of Perfume; Black Dog Publishing: London, UK, 2014; p. 51.

37. Harper, R. Some chemicals representing particular odour qualities. Chem. Senses 1975, 1, 353-357. [CrossRef]

38. Brud, W.S. Words versus odors: How perfumers communicate. Perfum. Flavorist 1986, 11, $27-44$.

39. Calkin, R.R.; Jellinek, J.S. Perfumery: Practice and Principles, 1st ed.; Wiley: New York, NY, USA, 1994.

40. Jellinek, P. Personal perfume selection. In The Psychological Basis of Perfumery, 4th ed.; Jellinek, J.S., Ed.; Chapman \& Hall: London, UK, 1997; pp. 153-161.

41. Fenko, A.; Schifferstein, H.N.J.; Huang, T.C.; Hekkert, P. What makes products fresh: The smell or the colour? Food Qual. Prefer. 2009, 20, 372-379. [CrossRef]

42. Mensing, J.; Beck, C. The psychology of fragrance selection. In Perfumery: The Psychology and Biology of Fragrance; Van Toller, S., Dodd, G.H., Eds.; Chapman \& Hall: London, UK, 1988; pp. 185-204.

43. Yokoyama, K.; Ebisawa, F. Detection and evaluation of fragrances by human reactions using a chemical sensor based on adsorbate detection. Anal. Chem. 1993, 65, 673-677. [CrossRef]

44. Higuchi, T.; Shoji, K.; Hatayama, T. Multidimensional scaling of fragrances: A comparison between the verbal and non-verbal methods of classifying fragrances. Jpn. Psychol. Res. 2004, 46, 10-19. [CrossRef]

45. Lindqvist, A. Perfume preferences and how they are related to commercial gender classifications of fragrances. Chemosens. Percept. 2012, 5, 197-204. [CrossRef]

(C) 2019 by the author. Licensee MDPI, Basel, Switzerland. This article is an open access article distributed under the terms and conditions of the Creative Commons Attribution (CC BY) license (http://creativecommons.org/licenses/by/4.0/). 